\title{
Aves de três remanescentes florestais do norte do Estado do Paraná, sul do Brasil, com sugestões para a conservação e manejo
}

\author{
Marcos Ricardo Bornschein ${ }^{1,2}$ \\ Bianca Luiza Reinert ${ }^{1,3}$
}

\begin{abstract}
Birds from three forest remnants in the North of Paraná State, South of Brazil, with suggestions for conservation and management. One hundred eighty species in a preliminary inventory were identified. From these, 166 were in an area of 832.5 ha (Mata São Francisco State Park), 84 in another of 9.7 ha (Manoel Júlio de Almeida Municipal Forest) and 99 in the third remnant, briefly sampled, of 218 ha (Mata São Paulo). Comparing these numbers to inventories of nearby sites was considered that the larger area is poor in number of bird species, and believe this to be mainly due to the high degree of environmental degradation. Was considered that the smaller area is rich in birds, but its proximity ( 375 meters) to the third remnant certainly exerts strong influence. This paper presents the list of birds by site and with their relative frequency of occurrence. A new record for Paraná (Scarlet-headed Blackbird Amblyramphus holosericeus), two new ones for the interior of the state (Uniform Crake Amaurolimnas concolor and Yellow-lored Tody-flycatcher Todirostrum poliocephalum) and several other important records are commented (e.g. Red-legged Seriema Cariama cristata, Vinaceous Parrot Amazona vinacea, and Black-banded Owl Ciccaba huhula). Locally extinct species are discussed (e.g. Harpy Eagle Harpia harpyja), as well as the ones that colonized landscapes created by men (e.g. pastures, agricultural areas). When discussing Atlantic Forest endemism, some species were shown not to be endemic to this biome. Because the north of Paraná is almost totally deforested, the presence of the forest remnants by itself confer them great importance for conservation, besides the existence of species endemic to the Atlantic Forest and considered to be under the threat of extinction. Conservation and management measures are also proposed.
\end{abstract}

KEY WORDS. Birds, South of Brazil, Atlantic Forest endemics, colonization, conservation

A cobertura florestal original do Paraná perfazia quase $85 \%$ da sua superficie. Deste total, restava menos de $8 \%$ em 1990, o que representou um desmatamento de dez milhões de hectares (FUNDAÇÃo sOS MATA ATLÂNTICA 1992a). Este percentual de desflorestamento é similar ao verificado na Região Nordeste do Brasil (WORKSHOP - MATA ATLÂNTICA DO NORDESTE 1993), e é maior do que o constatado, por exemplo, no Estado vizinho de Santa Catarina, onde sobrava até 1990 pouco mais de $16 \%$ da cobertura original (FUNDAÇÃO SOS MATA ATLÂNTICA 1992b).

1) Mater Natura - Instituto de Estudos Ambientais, Curitiba, Paraná, Brasil.

Correspondências para: Avenida República Argentina 1927, ap. 904, 80620-010 Curitiba, Paraná, Brasil. E-mail: mbr@bbs2.sul.com.br

2) Bolsista da CAPES.

3) Bolsista do CNPq. 
Uma das regiões mais devastadas do Paraná é o norte do Estado, que sofreu um processo acelerado de colonização a partir da década de 30, resultando na quase completa substituição das florestas por áreas de cultivo de café (MAACK 1963). Atualmente, a paisagem rural local é dominada por plantações de soja, trigo e cana-de-açúcar e, em menor escala, por pastagens.

Hoje um remanescente com apenas 832,5 ha é o maior fragmento florestal do norte do Paraná (Tomé et al. 1999). A necessidade de protegê-lo veio ao conhecimento público especialmente pela iniciativa de uma organização não-governamental da região (Grupo Ecológico Vida Verde, de Cornélio Procópio). Como resultado deste e de outros esforços, uma empresa privada, envolvida na construção de duas barragens no rio Paranapanema (Canoas I e II), adquiriu aquela área e a doou para o Estado como compensação pelo alagamento de terras paranaenses. Em 1994, criou-se o Parque Estadual Mata São Francisco (Decreto n ${ }^{\circ} 4.333$, de 05 de dezembro de 1994), que foi implantado em 1998.

O município de Cornélio Procópio se destaca, além da existência daquele parque estadual, pela presença de outros dois fragmentos florestais, um de domínio privado com 218 ha e outro, de domínio público, com 9,7 ha.

Da região onde se inserem estes três remanescentes, são conhecidas algumas publicações que retratam a ornitofauna. STEFFAN (1975) estudou uma localidade no município de Londrina, mas sugere-se a desconsideração desta obra como fonte de registros de aves, dada a existência de inúmeros prováveis erros de identificação. Relacionou-se espécies características de outras regiões do Brasil [e.g. saracurasanã-dos-mangues Rallus longirostris Boddaert, 1783, Rallidae; beija-flor-violeta Colibri coruscans (Gould, 1846), Trochilidae] e espécies novas para o Paraná, das quais algumas de difícil reconhecimento [e.g. mãe-da-lua-gigante Nyctibius grandis (Gmelin, 1788), Nyctibiidae; bacurau-rabo-maculado Caprimulgus maculicaudus (Lawrence, 1862), Caprimulgidae; andorinha-azul Progne subis (Linnaeus, 1758), Hirundinidae; tempera-viola Saltator maximus (P.L.S. Müller, 1776), Emberizidae], enquanto uma não identificada e descrita no texto deve tratar-se do característico birro Melanerpes candidus. Do mesmo município, WeSTCOTT (1980) listou as aves não Passeriformes. Ainda para Londrina e localidades circunvizinhas, como Rolândia e Jacarezinho, existem menções de mais algumas espécies (ZIMMER 1936: 26; PINTO 1938: 62, 72, 85, etc., 1944: 55, 94, 111, etc., 1964: 55, 66, 89, etc.; SicK 1959, 1960, 1997: 446, 615; RUSCHI 1986: 238; NETO 1995; SCHERER-NETO \& Straube 1995; Bornschein et al. 1997; Anjos \& FERREIRA 1998). Por fim, destacam-se as publicações de ANJOS \& SCHUCHMANN (1997) e ANJOS et al. (1997), que apresentaram listagens das aves da bacia hidrográfica do rio Tibagi por localidade, das quais algumas situam-se no norte do Paraná.

Efetuou-se o inventário das aves dos três fragmentos florestais mencionados, cujos resultados preliminares são apresentados neste trabalho, como também aspectos para a conservação das aves e manejo das áreas.

\section{MATERIAL E MÉTODOS}

Amostrou-se o Parque Estadual Mata São Francisco (doravante P.E.), com 832,5 ha, a Mata São Paulo (doravante M.S.P.), com 218 ha e o Bosque Municipal Manoel Júlio de Almeida (doravante B.M.), com 9,7 ha (veja as caracterizações 
mais adiante), considerando os registros efetuados no interior e no entorno destes fragmentos florestais (Fig. 1).

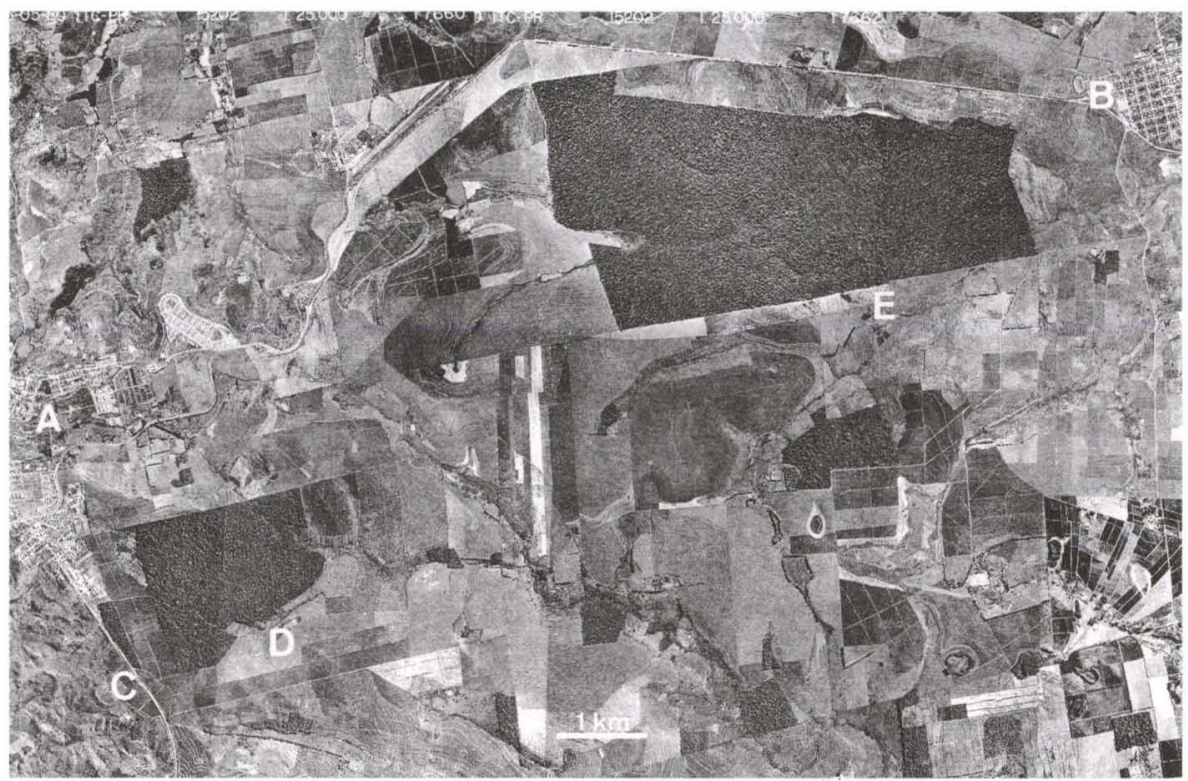

Fig. 1. Mosaico não controlado de fotos aéreas (vôo de 1980; escala 1: 25.000) mostrando parte das cidades de Cornélio Procópio (A) e Santa Mariana (B), norte do Estado do Paraná, e os fragmentos florestais estudados: Bosque Municipal Manoel Júlio de Almeida (C), Mata São Paulo (D) e Parque Estadual Mata São Francisco (E). O tamanho das cidades e a cobertura florestal conservada em outros fragmentos não condiz com a realidade atual. $\mathrm{O}$ topo da figura está orientado para o norte.

As atividades de campo foram realizadas em 1998 e totalizaram cerca de 105 h de trabalhos, das quais 66 h no P.E. (63\%), 28 h no B.M. (27\%) e 11 h na M.S.P. (10\%), distribuídas nas seguintes campanhas: 15-20 de fevereiro, 06-09 de julho e 07-10 de outubro.

Aplicaram-se os métodos usuais em trabalhos de inventário ornitofaunístico, realizando-se observações auxiliadas por binóculos $(10 \times 40 \mathrm{~mm})$, identificando-se espécies através do reconhecimento de suas vocalizações e efetuando-se capturas com redes ornitológicas.

Para a identificação auditiva das juritis (gênero Leptotila), adotou-se a proposta de Vechi e Vielliard (divulgada no V Congresso Brasileiro de Ornitologia, p. 124 do livro de resumos, Campinas, 1996). No esforço de captura, despendeu-se $18 \mathrm{~h}$ empregando-se no máximo oito redes ornitológicas.

Com o intuito de comprovar registros de aves, fotografou-se os exemplares capturados e gravou-se as vocalizações de muitas espécies, utilizando-se aparelho Sony TCM-5000 e microfone direcional Sennheiser ME-66. 
Na citação e listagem das aves, sumariada na tabela I, adotou-se a taxonomia e ordem filogenética de SICK (1997), exceto quanto ao pica-pau-anão-de-coleira Picumnus temminckii, para o qual foi seguido Sibley \& MONROE (1990). Obtiveram-se nomes comuns localmente, mas a grande maioria foi extraída de SICK (1997), dos quais simplificou-se alguns para adaptá-los à realidade regional. De SiCK (1985), colheu-se o nome do pica-pau-anão-de-coleira. Os nomes comuns em inglês, citados no resumo, seguem Sibley \& MONROE (1990).

Na tabela I, relacionou-se as espécies por localidade, freqüência de ocorrência, ambiente e período de registro. A freqüência de ocorrência indica (em porcentagem) a quantidade relativa de dias de campo que cada espécie foi registrada, os quais totalizaram 12 para o P.E., nove para o B.M. e cinco para a M.S.P. O tempo de amostragem não foi homogêneo em cada dia, variando desde um período inteiro a apenas uma hora.

O ambiente de observação foi dividido da seguinte forma: floresta; cultivo/pastagem (inclui locais com arbustos e árvores isoladas); banhado; aéreo (usado para as espécies que passam muito tempo em vôo); e aquático (corpos d'água dos açudes). Considerou-se algumas espécies características do hábito aéreo para outros ambientes, quando vistas, por exemplo, sobrevoando um açude ou pousadas em árvores no meio de pastagens.

\section{Caracterização da região de estudo}

Segundo os critérios para a classificação climática propostos por Koeppen, a região de estudo enquadra-se no tipo $\mathrm{Cfa}(\mathrm{h})$, ou periodicamente Cwa (MAACK 1963, 1981). Caracteriza-se pelo clima chuvoso temperado quente (um clima tropical modificado pela altitude), sempre úmido ou com períodos mais secos no inverno, por apresentar mais de $22^{\circ} \mathrm{C}$ no mês mais quente e por serem as geadas raras (MAACK 1981). A pluviosidade média é de 1.300-1.400 $\mathrm{mm}$ ao ano, sendo janeiro o mês mais chuvoso, com média de 175-200 mm e agosto o mês mais seco, com média de 50-75 mm (IAPAR 1978).

Conforme o mapa fitogeográfico do Paraná (MAACK 1950), a floresta é o único ambiente natural da região. Segundo os critérios para a classificação da vegetação brasileira propostos pelo projeto RADAMBRASIL (in VELOSO et al. 1991), ela denomina-se "Floresta Estacional Semidecidual" (RODERJAN et al. 1993).

\section{Os três fragmentos}

O P.E. (c. $23^{\circ} 08^{\prime}$ S, $50^{\circ} 34^{\prime} \mathrm{W}$; c. $350 \mathrm{~m}$ s.n.m.) localiza-se nos municípios de Santa Mariana e Cornélio Procópio. É cortado por alguns córregos e composto por floresta primária alterada, duas manchas de brejo, ao menos dois trechos de capoeira em estágio avançado de regeneração e por algumas áreas de agricultura, que foram incorporadas ao parque para permitir a instalação de infra-estrutura. É ilhado por pastagens e zonas de cultivo, especialmente de cana-de-açúcar e café, distando em torno de 1,5 km da M.S.P. No seu entorno existem ainda açudes e banhados de origem antrópica (banhados secundários), formados após o represamento de córregos.

A floresta apresenta altura média de aproximadamente $25 \mathrm{~m}$, havendo árvores emergentes com cerca de $35 \mathrm{~m}$. Um estudo revelou a presença de 85 espécies 
Tabela I. Aves registradas no Parque Estadual Mata São Francisco (P.E.), na Mata São Paulo (M.S.P.) e no Bosque Municipal Manoel Júlio de Almeida (B.M.), norte do Paraná (Brasil), relacionadas por área, freqüência de ocorrência (em porcentagem), ambiente (Amb.) e periodo de registro. Ambientes: (1) floresta, (2) cultivo/pastagem, (3) banhado, (4) aéreo e (5) aquático. Periodos: (A) 15-20/II/98, (B) 06-09NII/98 e (C) 07-10/X/98. Simbolos: (X) espécie registrada no entorno das reservas P.E. e B.M., $\left(^{*}\right)$ espécie endêmica da floresta atlântica (sensu lato), (\#) vide comentários no texto. Taxonomia segundo Sick (1997) e SiblEy \& MonROE-JR. (1990) para o pica-pau-anão-de-coleira Picumnus temminckii.

\begin{tabular}{|c|c|c|c|c|c|c|c|c|}
\hline \multirow{2}{*}{ Táxons } & \multirow{2}{*}{ Nome comum } & \multicolumn{3}{|c|}{ Área - Freqüência (\%) } & \multirow{2}{*}{ Amb. } & \multicolumn{3}{|c|}{ Periodo } \\
\hline & & P.E. & M.S.P. & B.M. & & A & B & C \\
\hline \multicolumn{9}{|l|}{ Tinamidae } \\
\hline Crypturellus obsoletus (Temminck, 1815) & Inhambu-guaçu & $X-58$ & - & - & 1 & $x$ & $\mathrm{x}$ & $\mathrm{X}$ \\
\hline Crypturellus parvirostris (Wagler, 1827) & Inhambu-chororo & $X-25$ & $X-40$ & $(X)-44$ & 1,2 & $x$ & $x$ & $x$ \\
\hline Crypturellus tataupa (Temminck, 1815) & Inhambu-chintă & $x-67$ & - & - & 1 & $\mathrm{x}$ & $x$ & $\mathrm{X}$ \\
\hline Nothura maculosa (Temminck, 1815) & Codorna-comum & - & $x-40$ & $(X)-11$ & 2 & $x$ & - & $x$ \\
\hline \multicolumn{9}{|l|}{ Podicipedidae } \\
\hline $\begin{array}{l}\text { Tachybaptus dominicus (Linnaeus, 1766) } \\
\text { Ardeidae }\end{array}$ & & - \\
\hline Bubulcus ibis (Linnaeus, 1758) & Garça-vaqueira & $(X)-8$ & - & - & 2 & - & - & $x$ \\
\hline Butorides striatus (Linnaeus, 1758) & Socozinho & $(X)-8$ & - & - & 3 & - & $x$ & - \\
\hline \multicolumn{9}{|l|}{ Cathartidae } \\
\hline Sarcoramphus papa (Linnaeus, 1758) & Urubu-rei & $x-8$ & - & - & 4 & $\mathrm{x}$ & - & - \\
\hline Coragyps atratus (Bechstein, 1793) & Urubu-de-cabeça-preta & $X-33$ & $x-20$ & $x-33$ & 1.4 & $x$ & $x$ & $x$ \\
\hline Cathartes aura Linnaeus, 1758 & Urubu-de-cabeça-vermelha & $\mathrm{X}-8$ & - & - & 4 & $\mathrm{x}$ & - & - \\
\hline \multicolumn{9}{|l|}{ Anatidae } \\
\hline Amazonetta brasiliensis (Gmelin, 1789) & Pé-vermelho & $(X)-8$ & - & - & 5 & - & $x$ & - \\
\hline \multicolumn{9}{|l|}{ Accipitridae } \\
\hline Leptodon cayanensis (Latham, 1790) & Gavião-de-cabeça-cinza \# & $x$ & - & - & 1 & $x$ & - & - \\
\hline Harpagus diodon (Temminck, 1823) & Gavião-bombachinha & - & - & $x-11$ & 1 & $\mathrm{X}$ & - & - \\
\hline Ictinia plumbea (Gmelin, 1788) & Sovi & $X-25$ & - & $x-11$ & 1,4 & - & - & $x$ \\
\hline Buteo brachyurus Vieillot, 1816 & Gaviăo-de-cauda-curta & $X-33$ & - & - & 4 & $x$ & $x$ & $x$ \\
\hline Rupornis magnirostris (Gmelin, 1789) & Gavião-carijó & $x-42$ & $x-20$ & $x-11$ & 1 & $\mathrm{x}$ & - & $x$ \\
\hline \multicolumn{9}{|l|}{ Falconidae } \\
\hline Polyborus plancus (Miller, 1777) & Caracará, carancho & $x-17$ & - & - & 1,2 & - & - & $x$ \\
\hline \multicolumn{9}{|l|}{ Cracidae } \\
\hline Penelope superciliaris Temminck, 1815 & Jacupemba & - & $x-40$ & $x-55$ & 1 & $x$ & $x$ & $x$ \\
\hline Penelope obscura Temminck, 1815 & Jacuguaçu & - & - & $x-22$ & 1 & $x$ & $x$ & - \\
\hline \multicolumn{9}{|l|}{ Rallidae } \\
\hline Rallus nigricans Vieillot, 1819 & Saracura-sană & $X-33$ & $X-20$ & - & 3 & $x$ & $x$ & $x$ \\
\hline Amaurolimnas concolor (Gosse, 1847) & Saracurinha-da-mata & $X-8$ & - & - & 3 & - & - & $x$ \\
\hline Aramides saracura (Spix, 1825) * & Saracura-do-mato & $x-8$ & $\mathrm{X}-20$ & - & 1 & $\mathrm{x}$ & $x$ & - \\
\hline Porzana albicollis (Vieillot, 1819) & Sană-carijó & $(X)-8$ & - & - & 3 & - & - & $x$ \\
\hline Laterallus melanophaius (Vieillot, 1819) & Pinto-d'água-comum & $X-25$ & $X-20$ & - & 3 & $\mathrm{x}$ & $x$ & $x$ \\
\hline Gallinula chloropus (Linnaeus, 1758) & Frango-d'água-comum & $(X)-8$ & - & - & 5 & - & $x$ & - \\
\hline \multicolumn{9}{|l|}{ Cariamidae } \\
\hline \multicolumn{8}{|l|}{ Jacanidae } & - \\
\hline Jacana jacana (Linnaeus, 1758) & Jaçană & $(X)-8$ & - & - & 5 & - & $x$ & - \\
\hline \multicolumn{9}{|l|}{ Charadriidae } \\
\hline Vanellus chilensis (Molina, 1782) & Quero-quero & $X-42$ & $x-40$ & $(X)-11$ & 2 & $x$ & $x$ & $x$ \\
\hline \multicolumn{9}{|l|}{ Columbidae } \\
\hline Columba picazuro Temminck, 1813 & Asa-branca & $\mathrm{X}-92$ & $x-80$ & $x-78$ & 1,2 & $x$ & $\mathrm{x}$ & $x$ \\
\hline Columba cayennensis Bonnaterre, 1792 & Pomba-galega & $x-17$ & - & $x-11$ & 1 & - & $x$ & $x$ \\
\hline Zenaida auriculata (Des Murs, 1847) & Avoante, amargosa & $x-42$ & $x-40$ & $x-11$ & 1,2 & $x$ & $\mathrm{x}$ & $x$ \\
\hline Columbina talpacoti (Temminck, 1811) & Rola & $x-33$ & $x-60$ & $x-33$ & 1,2 & $x$ & $x$ & $x$ \\
\hline Columbina picui (Temminck, 1813) & Rolinha-branca & $x-17$ & $x-40$ & $x-11$ & 2 & $x$ & $x$ & - \\
\hline Leptotila verreauxi Bonaparte, 1855 & Juriti & $X-75$ & $x-20$ & $x-22$ & 1,2 & $x$ & $x$ & $x$ \\
\hline Geotrygon sp. & Juriti & $x-17$ & - & - & 1 & $x$ & - & - \\
\hline \multicolumn{9}{|l|}{ Psittacidae } \\
\hline Aratinga leucophthaimus (Müller, 1776) & Maritaca & $X-83$ & $x-60$ & $x-44$ & 1,2 & $x$ & $x$ & $x$ \\
\hline Pyrrhura frontalis (Vieillot, 1817) & Tiriba & $x-75$ & $X-80$ & $x-33$ & 1. 2 & $x$ & $x$ & $\mathrm{x}$ \\
\hline
\end{tabular}


Tabela I. Continuação.

\begin{tabular}{|c|c|c|c|c|c|c|c|c|}
\hline \multirow{2}{*}{ Táxons } & \multirow{2}{*}{ Nome comum } & \multicolumn{3}{|c|}{ Área - Frequeência (\%) } & \multirow{2}{*}{$-A m b$. } & \multicolumn{3}{|c|}{ Periodo } \\
\hline & & P.E. & M.S.P. & B.M. & & A & B & C \\
\hline Forpus xanthopterygius (Spix, 1824) & Tuim & $x-8$ & - & $X-22$ & 1 & - & $\mathrm{x}$ & $x$ \\
\hline Brotogeris tirica (Gmelin, 1788) * & Periquito-rico & $\mathrm{X}-8$ & $x-40$ & - & 1,2 & $x$ & - & $x$ \\
\hline Pionopsitta pileata (Scopoli, 1767) * & Cuiú-cuiú & $x-8$ & - & - & 1 & - & $\mathrm{x}$ & - \\
\hline Pionus maximiliani (Kuhl, 1820) & Maitaca & $X-83$ & $x-60$ & $X-89$ & 1 & $x$ & $x$ & $x$ \\
\hline Amazona vinacea (Kuhl, 1820) * & Papagaio-de-peito-roxo & $\mathrm{X}-8$ & - & - & 1 & $x$ & - & - \\
\hline \multicolumn{9}{|l|}{ Cuculidae } \\
\hline Piaya cayana (Linnaeus, 1766) & Alma-de-gato & $X-75$ & $x-60$ & $x-67$ & 1,2 & $x$ & $x$ & $x$ \\
\hline Crotophaga ani Linnaeus, 1758 & Anu-preto & $x-67$ & - & $(X)-11$ & 2,3 & $x$ & $\mathrm{x}$ & $x$ \\
\hline Guira guira (Gmelin, 1788) & Anu-branco & $x-42$ & $x-20$ & $x-33$ & 1,2 & $\mathrm{x}$ & $x$ & $x$ \\
\hline Tapera naevia (Linnaeus. 1766) & Saci & $(X)-8$ & - & $(X)-44$ & 2 & $x$ & $x$ & $x$ \\
\hline \multicolumn{9}{|l|}{ Strigidae } \\
\hline Otus choliba (Vieillot, 1817) & Corujinha-do-mato & $\mathrm{X}-8$ & $x-20$ & - & 1 & - & $x$ & $x$ \\
\hline $\begin{array}{l}\text { Pulsatrix koeniswaldiana (Bertoni \& Bertoni, } \\
\text { 1901) * }\end{array}$ & Murucututu & - & $X-40$ & $\mathrm{X}-11$ & 1 & $x$ & - & $x$ \\
\hline Glaucidium brasilianum (Gmelin, 1788) & Caburé & $x-17$ & - & - & 1 & - & - & $x$ \\
\hline Speotyto cunicularia (Molina, 1782) & Coruja-buraqueira & $x-33$ & - & $x-22$ & 2 & $x$ & $x$ & $x$ \\
\hline Ciccaba huhula (Daudin, 1800) & Coruja-preta \# & $x$ & - & - & 1 & - & $\mathrm{x}$ & - \\
\hline cf. Strix hylophila Temminck, $1825^{*}$ & Coruja-listrada & - & $x-20$ & - & 1 & - & - & $x$ \\
\hline \multicolumn{9}{|l|}{ Nyctibiidae } \\
\hline Nyctibius griseus (Gmelin, 1789) & Urutau, mãe-da-lua & $x-8$ & $x-20$ & - & 1 & - & $x$ & $x$ \\
\hline \multicolumn{9}{|l|}{ Caprimulgidae } \\
\hline Lurocalis semitorquatus (Gmelin, 1788) & Tuju & $x-8$ & - & $X-55$ & 1,4 & $x$ & - & $x$ \\
\hline Nyctidromus albicollis (Gmelin, 1789) & Curiango, bacurau & $X-17$ & $x-40$ & - & 1 & $x$ & $x$ & $x$ \\
\hline \multicolumn{9}{|l|}{ Apodidae } \\
\hline Streptoprocne zonaris (Shaw, 1796) & Andorinhão-de-coleira & $X-25$ & - & - & $1,2,4$ & - & $x$ & $x$ \\
\hline cf. Cypseloides senex (Temminck, 1826) & Andorinhăo-velho-da-cascata & $x-8$ & - & - & 2,4 & - & - & $x$ \\
\hline Chaetura cinereiventris Sclater, 1862 & $\begin{array}{l}\text { Andorinhăo-de-sobre-cin- } \\
\text { zento }\end{array}$ & $X-33$ & $x-20$ & - & 1,4 & - & $\mathrm{x}$ & $\mathrm{x}$ \\
\hline \multicolumn{8}{|l|}{ Trochilidae } & $x$ \\
\hline Phaethomis squalidus (Temminck, 1822) * & Rabo-branco-miúdo & $x-42$ & $x-20$ & - & 1 & $x$ & $\mathrm{x}$ & $x$ \\
\hline Eupetomena macroura (Gmelin, 1788) & Tesourăo & - & - & $X-11$ & 1 & - & - & $x$ \\
\hline Melanotrochilus fuscus (Vieillot, 1817) * & Beija-flor-preto-e-branco & $x-8$ & - & - & 1 & - & $x$ & - \\
\hline $\begin{array}{l}\text { Chlorostilbon aureoventris (d'Orbigny \& } \\
\text { Lafresnaye, 1838) }\end{array}$ & Besourinho-de-bico-vermelho & $x-8$ & $x-20$ & - & 2 & $x$ & - & $x$ \\
\hline Thalurania glaucopis (Gmelin, 1788) * & Tesoura-de-fronte-violeta & $x-8$ & $x-40$ & $x-11$ & 1 & $x$ & $\mathrm{x}$ & $x$ \\
\hline Amazilia fimbriata (Gmelin, 1788) & Beija-flor-de-garganta-verde & $X-25$ & - & - & 1 & $x$ & $\mathrm{x}$ & - \\
\hline Amazilia lactea (Lesson, 1832) & Beija-flor-de-peito-azul & $\mathrm{X}-17$ & - & $x-33$ & 1 & $x$ & - & $\mathrm{x}$ \\
\hline \multicolumn{9}{|l|}{ Trogonidae } \\
\hline Trogon surrucura Vieillot, 1817 & Surucuá-de-peito-azul & $X-17$ & $x-40$ & - & 1 & $x$ & $x$ & $x$ \\
\hline \multicolumn{9}{|l|}{ Alcedinidae } \\
\hline Chloroceryle americana (Gmelin, 1788) & Martim-pescador-pequeno & $(X)-8$ & - & - & 1 & - & $x$ & - \\
\hline \multicolumn{9}{|l|}{ Momotidae } \\
\hline Baryphthengus ruficapillus (Vieillot, 1818) & Juruva & $x-8$ & $x-20$ & - & 1 & - & $\mathrm{x}$ & $x$ \\
\hline \multicolumn{9}{|l|}{ Ramphastidae } \\
\hline Selenidera maculirostris (Lichtenstein, 1823) * & *Araçari-poca & $x-8$ & - & - & 1 & $x$ & - & - \\
\hline Baillonius bailloni (Vieillot, 1819) * & Araçari-banana & $X-25$ & - & - & 1 & - & $\mathrm{x}$ & $x$ \\
\hline \multicolumn{9}{|l|}{ Picidae } \\
\hline Picumnus temminckii Lafresnaye, $1845^{*}$ & Pica-pau-anão-de-coleira & $\mathrm{X}-92$ & $X-40$ & - & 1 & $x$ & $\mathrm{x}$ & $x$ \\
\hline Colaptes campestris (Vieillot, 1818) & Pica-pau-do-campo & $X-17$ & $x-20$ & - & 2 & $x$ & $\mathrm{x}$ & - \\
\hline Colaptes melanochloros (Gmelin, 1788) & Pica-pau-verde-barrado & $x-33$ & $x-20$ & - & 1 & - & $x$ & $x$ \\
\hline Celeus flavescens (Gmelin, 1788) & Pica-pau-de-cabeça-amarela & $\mathrm{X}-8$ & - & - & 1 & - & - & $\mathrm{x}$ \\
\hline Dryocopus lineatus (Linnaeus, 1766) & Pica-pau-de-banda-branca & $X-33$ & $x-20$ & $x-11$ & 1 & $x$ & $\mathrm{x}$ & $\mathrm{x}$ \\
\hline Melanerpes flavifrons (Vieillot, 1818) & Benedito & $x-75$ & $x-60$ & - & 1 & $x$ & $x$ & $x$ \\
\hline Melanerpes candidus (Otto, 1796) & Birro & $\mathrm{X}-33$ & $x-20$ & $x-33$ & 1,2 & $x$ & $x$ & $x$ \\
\hline Veniliornis spilogaster (Wagler, 1827) & Pica-pauzinho-verde-carijó & $x-83$ & $x-80$ & $X-55$ & 1 & $x$ & $\mathrm{x}$ & $\mathrm{x}$ \\
\hline Campephilus robustus (Lichtenstein, 1819) * & Pica-pau-rei & $x-8$ & - & - & 1 & - & $x$ & - \\
\hline
\end{tabular}


Tabela I. Continuação.

\begin{tabular}{|c|c|c|c|c|c|c|c|c|}
\hline \multirow{2}{*}{ Táxons } & \multirow{2}{*}{ Nome comum } & \multicolumn{3}{|c|}{ Área - Frequéncia (\%) } & \multirow{2}{*}{ - Amb. - } & \multicolumn{3}{|c|}{ Período } \\
\hline & & P.E. & M.S.P. & B.M. & & A & B & C \\
\hline \multicolumn{9}{|l|}{ Thamnophilidae } \\
\hline Hypoedaleus guttatus (Vieillot, 1816) * & Chocăo-carijó & $x-100$ & $x-60$ & - & 1 & $\mathrm{X}$ & $x$ & $x$ \\
\hline Batara cinerea (Vieillot, 1819) & Matracăo & - & $x-20$ & - & 1 & $x$ & - & - \\
\hline Mackenziaena severa (Lichtenstein, 1823) * & * Borralhara & $x-92$ & $x-60$ & - & 1 & $\mathrm{x}$ & $x$ & $x$ \\
\hline Thamnophilus doliatus (Linnaeus, 1764) & Choca-barrada & $X-17$ & $x-40$ & - & 2 & $x$ & $x$ & $x$ \\
\hline Thamnophilus caerulescens (Vieillot, 1816) & Choca-da-mata & $X-50$ & $x-40$ & $x-44$ & 1 & $\mathrm{x}$ & $x$ & $x$ \\
\hline Thamnophilus ruficapillus (Vieillot, 1816) & Choca-de-chapéu-vermelho & - & - & $(\mathrm{X})-11$ & 2 & - & $x$ & - \\
\hline Dysithamnus mentalis (Temminck, 1823) & Choquinha-lisa & $\mathrm{X}-92$ & $x-60$ & $\mathrm{X}-89$ & 1 & $x$ & $x$ & $x$ \\
\hline $\begin{array}{l}\text { Herpsilochmus rufimarginatus (Temminck, } \\
\text { 1822) }\end{array}$ & Chororozinho-de-asa-vermelha & $X-58$ & $x-40$ & $X-89$ & 1 & $x$ & $x$ & $x$ \\
\hline $\begin{array}{l}\text { Pyriglena leucoptera (Vieillot, 1818) * } \\
\text { Formicariidae }\end{array}$ & Papa-taoca & $x-83$ & - & - & 1 & $x$ & $x$ & $x$ \\
\hline $\begin{array}{l}\text { Chamaeza campanisona (Lichtenstein, } \\
\text { 1823) }\end{array}$ & Tovaca-campainha & $x-42$ & - & - & 1 & $x$ & $\mathrm{x}$ & $x$ \\
\hline \multicolumn{9}{|l|}{ Conopophagidae } \\
\hline Conopophaga lineata (Wied, 1831) & Chupa-dente & $x-50$ & $x-40$ & $x-67$ & 1 & $\mathrm{x}$ & $\mathrm{x}$ & $x$ \\
\hline \multicolumn{9}{|l|}{ Furnariidae } \\
\hline Furnarius rufus (Gmelin, 1788) & Joåo-de-barro & $x-17$ & $x-60$ & $(X)-11$ & 2 & $\mathrm{x}$ & - & $x$ \\
\hline Synallaxis ruficapilla Vieillot, $1819^{*}$ & Pichororé & $x-50$ & $x-40$ & - & 1 & $x$ & $x$ & $x$ \\
\hline Synallaxis frontalis Pelzeln, 1859 & Petrim & $x-8$ & - & $\mathrm{X}-11$ & 1 & $x$ & $x$ & - \\
\hline Philydor lichtensteini Cabanis \& Heine, 1859 & 9Limpa-folha-ocrácea & $x-58$ & - & $\mathrm{x}-11$ & 1 & $\mathrm{x}$ & $x$ & $x$ \\
\hline Automolus leucophthalmus (Wied, 1821) & Barranqueiro-de-olho-branco & $x-42$ & $x-40$ & - & 1 & $x$ & $x$ & $x$ \\
\hline Xenops rutilans Temminck, 1821 & Bico-virado-carijo & $x-42$ & $x-20$ & - & 1 & $x$ & $x$ & $x$ \\
\hline cf. Sclerurus scansor (Ménétriès, 1835) & Vira-folhas & $x-8$ & - & - & 1 & - & $x$ & - \\
\hline Lochmias nematura (Lichtenstein, 1823) & Joăo-porca & $x-8$ & - & - & 1 & - & $x$ & - \\
\hline \multicolumn{9}{|l|}{ Dendrocolaptidae } \\
\hline Sittasomus griseicapillus (Vieillot, 1818) & Arapaçu-verde & $x-17$ & - & - & 1 & $x$ & $x$ & - \\
\hline Xiphocolaptes albicollis (Vieillot, 1818) & Arapaçu-de-garganta-branca & $x-33$ & $x-20$ & $X-55$ & 1 & $x$ & $x$ & $x$ \\
\hline Dendrocolaptes platyrostris Spix, 1825 & Arapaçu-grande & $X-58$ & $x-60$ & $x-11$ & 1 & $x$ & $x$ & $x$ \\
\hline $\begin{array}{l}\text { Lepidocolaptes fuscus (Vieillot, 1818) " } \\
\text { Tyrannidae }\end{array}$ & Arapaçu-rajado & $x-83$ & - & - & 1 & $x$ & $\mathrm{x}$ & $x$ \\
\hline $\begin{array}{l}\text { Phyllomyias burmeisteri (Cabanis \& Heine, } \\
\text { 1859) }\end{array}$ & Poiaeiro-do-sul & - & - & $x-22$ & 1 & - & $x$ & $x$ \\
\hline Camptostoma obsoletum (Temminck, 1824) & Risadinha & $x-25$ & $x-20$ & $x-11$ & 1,2 & $x$ & $\mathrm{x}$ & $x$ \\
\hline Myiopagis viridicata (Vieillot, 1817) & Guaracava-de-olheiras & $X-58$ & - & - & 1 & - & $x$ & $x$ \\
\hline Myiopagis caniceps (Swainson, 1837) & Maria-da-copa & $X-58$ & $x-40$ & - & 1 & $x$ & $\mathrm{x}$ & $x$ \\
\hline Elaenia flavogaster (Thunberg, 1822) & Guaracava-de-barriga-amarela & $x-25$ & - & $x-11$ & $1,2,3$ & - & $x$ & $x$ \\
\hline $\begin{array}{l}\text { Elaenia obscura (d'Orbigny \& Lafresnaye, } \\
\text { 1837) }\end{array}$ & Tucăo & $x-8$ & - & - & 2 & - & $x$ & - \\
\hline Serpophaga subcristata (Vieillot, 1817) & Alegrinho & - & $X-20$ & $(X)-11$ & 2 & $x$ & $\mathrm{x}$ & - \\
\hline Leptopogon amaurocephalu Tschudi, 1846 & Cabeçudo & $x-75$ & - & - & 1 & $x$ & $\mathrm{x}$ & $x$ \\
\hline Capsiempis flaveola (Lichtenstein, 1823) & Marianinha-amarela & $X-25$ & - & - & 1 & - & $x$ & $x$ \\
\hline Corythopis delalandi (Lesson, 1831) & Estalador & $X-50$ & - & - & 1 & $x$ & $x$ & $x$ \\
\hline Myiornis auricularis (Vieillot, 1818) * & Miudinho & $x-75$ & $X-20$ & $x-44$ & 1 & $x$ & $\mathrm{x}$ & $x$ \\
\hline Todirostrum poliocephalum (Wied, 1831) * & Teque-teque & $X-67$ & $X-20$ & $x-11$ & 1 & $x$ & $x$ & $x$ \\
\hline Todirostrum cinereum (Linnaeus, 1766) & Relógio & $x-25$ & $x-20$ & $x-44$ & 1,2 & $x$ & $x$ & $x$ \\
\hline Tolmomyias sulphurescens (Spix, 1825) & Bico-chato-de-orelha-preta & $x-58$ & $x-80$ & $x-11$ & 1 & $x$ & $x$ & $x$ \\
\hline Platyrinchus mystaceus (Vieillot, 1818) & Patinho & $X-25$ & - & - & 1 & $x$ & $x$ & $\mathrm{x}$ \\
\hline Myiophobus fasciatus (Müller, 1776) & Filipe & - & $x-20$ & $\mathrm{X}-25$ & 1,2 & $x$ & $x$ & $x$ \\
\hline Contopus cinereus (Spix, 1825) & Papa-moscas-cinzento & $X-17$ & - & - & 1 & - & $\mathrm{x}$ & - \\
\hline Lathrotriccus euleri (Cabanis, 1868) & Enferrujado & $x-50$ & $x-20$ & $x-11$ & 1 & - & $x$ & $x$ \\
\hline Cnemotriccus fuscatus (Wied, 1831) & Guaracavuçu & $x-8$ & - & - & 1 & - & $x$ & - \\
\hline Arundinicola leucocephala (Linnaeus, 1764) & Lavadeira-de-cabeça-branca & $(X)-8$ & - & - & 3 & - & $x$ & - \\
\hline Colonia colonus (Vieillot, 1818) & Viuvinha & $x-42$ & $x-20$ & - & 1 & - & $x$ & $x$ \\
\hline Machetornis rixosus (Vieillot, 1819) & Bentevi-do-gado & $x-8$ & $x-20$ & $(X)-11$ & 2 & $x$ & $x$ & $x$ \\
\hline Sirystes sibilator (Vieillot, 1818) & Gritador & $x-58$ & - & - & 1 & $x$ & $x$ & $x$ \\
\hline Myiarchus ferox (Gmelin, 1789) & Maria-cavaleira & $X-8$ & $X-20$ & - & 1 & $x$ & $x$ & - \\
\hline $\begin{array}{l}\text { Myiarchus swainsoni Cabanis \& Heine, } \\
1859\end{array}$ & Irrê & $X-25$ & $x-20$ & $\mathrm{X}-11$ & 1 & $\mathrm{x}$ & - & $\mathrm{x}$ \\
\hline Pitangus, sulphuratus (Linnaeus, 1766) & Bentevi & $x-33$ & $x-20$ & $x-67$ & 1,2 & $x$ & $x$ & $x$ \\
\hline
\end{tabular}


Tabela I. Continuação.

\begin{tabular}{|c|c|c|c|c|c|c|c|c|}
\hline \multirow{2}{*}{ Táxons } & \multirow{2}{*}{ Nome comum } & \multicolumn{3}{|c|}{ Area - Freqüência (\%) } & \multirow{2}{*}{$A m b$} & \multicolumn{3}{|c|}{ Periodo } \\
\hline & & P.E. & M.S.P. & B.M. & & A & B & C \\
\hline Megarhynchus pitangua (Linnaeus, 1766) & Neinei & $\mathrm{X}-58$ & $x-20$ & $x-22$ & 1,2 & $x$ & $x$ & $x$ \\
\hline Myiozetetes similis (Spix, 1825) & Bentevizinho-penacho-vermelho & - & $X-20$ & - & 1 & $x$ & - & - \\
\hline Myiodynastes maculatus (Müller, 1776) & Bentevi-rajado & $x-33$ & $x-40$ & $x-44$ & 1 & $x$ & - & $x$ \\
\hline Legatus leucophaius (Vieillot, 1818) & Bentevi-pirata & $x-8$ & - & - & 1 & - & - & $x$ \\
\hline Empidonomus varius (Vieillot, 1818) & Peitica & $\mathrm{X}-25$ & $x-40$ & $x-33$ & 1. 2 & $x$ & - & $x$ \\
\hline Tyrannus savana Vieillot, 1808 & Tesourinha & $x-25$ & $x-20$ & $x-11$ & 1,2 & $x$ & - & $x$ \\
\hline Tyrannus melancholicus Vieillot, 1819 & Suiriri & $x-33$ & $x-20$ & $X-55$ & 1,2 & $x$ & - & $x$ \\
\hline Pachyramphus polychopterus (Vieillot, 1818) & Caneleiro-preto & $x-25$ & $x-20$ & - & 1 & $x$ & - & $x$ \\
\hline Pachyramphus validus (Lichtenstein, 1823) & Caneleiro-de-chapéu-negro & $x-8$ & $x-20$ & - & 1,2 & $x$ & - & $x$ \\
\hline Tityra cayana (Linnaeus, 1766 ) & Anambé-branco-de-rabo-preto & $x-33$ & $x-20$ & - & 1 & $x$ & $x$ & $x$ \\
\hline \multicolumn{9}{|l|}{ Pipridae } \\
\hline Chiroxiphia caudata (Shaw \& Nodder, 1793) * & Tangará & $X-50$ & $x-20$ & - & 1 & $\mathrm{x}$ & $x$ & $\mathrm{x}$ \\
\hline \multicolumn{9}{|l|}{ Hirundinidae } \\
\hline Tachycineta albiventer (Boddaert, 1783) & Andorinha-do-rio & $(X)-17$ & - & - & 4,5 & - & $x$ & $x$ \\
\hline Tachycineta leucorrhoa (Vieillot, 1817) & Andorinha-de-sobre-branco & $x-17$ & - & - & 2,4 & - & $x$ & $x$ \\
\hline Progne chalybea (Gmelin, 1789) & Andorinha-doméstica-grande & $x-8$ & $x-20$ & $x-22$ & $1,2,4$ & $x$ & - & - \\
\hline Notiochelidon cyanoleuca (Vieillot, 1817) & Andorinha-pequena-de-casa & $X-17$ & $x-20$ & $x-22$ & $1,2,4$ & $x$ & $x$ & $x$ \\
\hline Stelgidopteryx ruficollis (Vieillot, 1817) & Andorinha-serrador & $\mathrm{X}-17$ & - & - & $1,3,4$ & $x$ & $x$ & - \\
\hline \multicolumn{9}{|l|}{ Troglodytidae } \\
\hline Donacobius atricapillus (Linnaeus, 1766) & Japacanim & $x-42$ & $x-20$ & - & 3 & $x$ & $x$ & $\mathrm{x}$ \\
\hline Troglodytes aedon Vieillot, 1809 & Corruira & $X-50$ & $x-20$ & $X-11$ & $1,2,3$ & $x$ & $x$ & $x$ \\
\hline \multicolumn{9}{|l|}{ Muscicapidae } \\
\hline Turdus subalaris (Seebohm, 1887) * & Sabiá-ferreiro & $X-25$ & - & - & 1 & - & - & $x$ \\
\hline Turdus rufiventris Vieillot, 1818 & Sabiá-laranjeira & $x-25$ & $x-40$ & $x-33$ & 1 & $x$ & $x$ & $x$ \\
\hline Turdus leucomelas Vieillot, 1818 & Sabiá-barranco & $x-33$ & $x-40$ & $x-89$ & 1,2 & $x$ & $x$ & $x$ \\
\hline Turdus amaurochalinus Cabanis, 1851 & Sabiá-poca & $x-42$ & - & $x-22$ & 1 & - & $x$ & $x$ \\
\hline Turdus albicollis Vieillot, 1818 & Sabiá-coleira & $x-25$ & - & - & 1 & - & - & $x$ \\
\hline \multicolumn{9}{|l|}{ Mimidae } \\
\hline Mimus saturninus (Lichtenstein, 1823) & Sabiá-do-campo & $\mathrm{x}-17$ & - & - & 2 & $x$ & $x$ & - \\
\hline \multicolumn{9}{|l|}{ Motacillidae } \\
\hline Anthus lutescens Pucheran, 1855 & Caminheiro-zumbidor & $x-33$ & - & - & 2 & - & $x$ & $x$ \\
\hline \multicolumn{9}{|l|}{ Vireonidae } \\
\hline Cyclarhis gujanensis (Gmelin, 1789) & Pitiguari & $x-100$ & $x-80$ & $x-42$ & 1 & $x$ & $x$ & $x$ \\
\hline Vireo chivi (Vieillot, 1817) & Juruviara & $x-58$ & $x-20$ & $x-44$ & 1 & $x$ & - & $x$ \\
\hline \multicolumn{9}{|l|}{ Emberizidae - Parulinae } \\
\hline Parula pitiayumi (Vieillot, 1817) & Mariquita & $x-42$ & $x-40$ & $x-67$ & 1 & $x$ & $\mathrm{x}$ & $x$ \\
\hline Geothlypis aequinoctialis (Gmelin, 1789) & Pia-cobra & $x-42$ & $x-20$ & - & 3 & $x$ & $x$ & $x$ \\
\hline Basileuterus flaveolus (Baird, 1865) & Canário-do-mato & $x-8$ & - & - & 1 & $x$ & - & - \\
\hline Basileuterus culicivorus (Deppe, 1830) & Pula-pula, tisso & $x-100$ & $x-40$ & $x-78$ & 1 & $x$ & $x$ & $x$ \\
\hline \multicolumn{9}{|l|}{ Emberizidae - Thraupinae } \\
\hline Cissopis leveriana (Gmelin, 1788) & Tietinga & $x-8$ & $X-20$ & - & 1 & $\mathrm{x}$ & $x$ & - \\
\hline Hemithraupis guira (Linnaeus, 1766) & Saira-de-papo-preto & $x-83$ & $x-40$ & $x-89$ & 1 & $x$ & $x$ & $x$ \\
\hline Tachyphonus coronatus (Vieillot, 1822) & Tiê-preto & $x-42$ & - & - & 1 & - & $x$ & $x$ \\
\hline Trichothraupis melanops (Vieillot, 1818) & Tiè-de-topete & $x-83$ & $x-60$ & $x-67$ & 1 & $x$ & $x$ & $x$ \\
\hline Habia rubica (Vieillot, 1817) & Tiè-do-mato-grosso & $x-92$ & $x-40$ & $x-11$ & 1 & $x$ & $x$ & $x$ \\
\hline Ramphocelus carbo (Pallas, 1764) & Pipira-vermelha & $x-8$ & - & - & 1 & - & $x$ & - \\
\hline Thraupis sayaca (Linnaeus, 1766) & Sanhaço-cinzento & $x-33$ & $x-20$ & $X-55$ & 1,2 & $x$ & $x$ & $x$ \\
\hline cf. Thraupis palmarum (Wied, 1821) & Sanhaço-do-coqueiro & - & - & $x-11$ & 1 & - & - & $x$ \\
\hline Pipraeidea melanonota (Vieillot, 1819) & Viúva & $x-8$ & - & - & 1 & - & $x$ & - \\
\hline Euphonia chlorotica (Linnaeus, 1776) & Fi-fi-verdadeiro & $x-50$ & - & $X-55$ & 1 & $x$ & $x$ & $x$ \\
\hline Dacnis cayana (Linnaeus, 1766) & Sai-azul & $x-17$ & $x-20$ & $x-22$ & 1,2 & $x$ & $x$ & $x$ \\
\hline Conirostrum speciosum (Temminck, 1824) & Figuinha-de-rabo-castanho & $x-58$ & $x-20$ & $x-33$ & 1 & $x$ & $x$ & $x$ \\
\hline cf. Tersina viridis (Illiger, 1811) & Sai-andorinha & $x-8$ & - & - & 1 & - & - & $x$ \\
\hline \multicolumn{9}{|l|}{ Emberizidae - Emberizinae } \\
\hline Zonotrichia capensis (Muller, 1776) & Tico-tico & $x-8$ & - & - & 2 & - & - & $x$ \\
\hline Ammodramus humeralis (Bosc, 1792) & Tico-tico-do-campo & $x-8$ & - & $(\mathrm{X})-22$ & 2 & - & - & $x$ \\
\hline Volatinia jacarina (Linnaeus, 1766) & Tiziu & $x-50$ & - & $(\mathrm{X})-11$ & 2 & $x$ & - & $x$ \\
\hline Sporophila caerulescens (Vieillot, 1817) & Coleirinho & $x-25$ & $x-20$ & - & 2,3 & $x$ & - & $x$ \\
\hline
\end{tabular}


Tabela I. Continuação.

\begin{tabular}{|c|c|c|c|c|c|c|c|c|}
\hline \multirow{2}{*}{ Táxons } & \multirow{2}{*}{ Nome comum } & \multicolumn{3}{|c|}{ Área - Frequència (\%) } & \multirow{2}{*}{ Amb. } & \multicolumn{3}{|c|}{ Periodo } \\
\hline & & P.E. & M.S.P. & B.M. & & A & B & C \\
\hline Tiaris fuliginosa (Wied, 1831) & Cigarra-do-coqueiro & $\mathrm{X}-25$ & $x-20$ & - & 1 & $\mathrm{x}$ & $x$ & $\hat{n}$ \\
\hline Arremon flavirostris Swainson, 1837 & $\begin{array}{l}\text { Tico-tico-do-mato-de-bico- } \\
\text { amarelo }\end{array}$ & $x-25$ & - & - & 1 & - & $x$ & $x$ \\
\hline cf. Coryphospingus cucullatus (Müller, 1776) & Tico-tico-rei & $(X)-8$ & - & - & 2 & $\mathrm{x}$ & - & - \\
\hline \multicolumn{9}{|l|}{ Emberizidae - Cardinalinae } \\
\hline Pitylus fuliginosus (Daudin, 1800) * & Pimentão & - & - & $x-11$ & 1 & - & - & $x$ \\
\hline $\begin{array}{l}\text { Saltator similis Lafresnaye \& d'Orbigny, } 1837 \\
\text { Emberizidae - Icterinae }\end{array}$ & Trinca-ferro-verdadeiro & $x-17$ & $x-20$ & $x-11$ & 1 & $x$ & - & $x$ \\
\hline Cacicus haemorrhous (Linnaeus, 1766) & Guaxe & - & $x-20$ & - & 1 & $\mathrm{x}$ & - & - \\
\hline Leistes superciliaris (Bonaparte, 1851) & Policia-inglesa & $x-8$ & - & - & 2 & - & - & $x$ \\
\hline Amblyramphus holosericeus (Scopoli, 1786) & Cardeal-do-banhado & $x-8$ & - & - & 3 & - & - & $x$ \\
\hline Molothrus bonariensis (Gmelin, 1789) & Chopim, vira-bosta & $x-8$ & - & $\mathrm{X}-11$ & 1,2 & - & - & $x$ \\
\hline \multicolumn{9}{|l|}{ Passeridae } \\
\hline Passer domesticus (Linnaeus, 1758) & Pardal & $\mathrm{X}-8$ & $x-40$ & $x-22$ & 1,2 & $x$ & $\mathrm{x}$ & $x$ \\
\hline Total & & 166 & 99 & 84 & $A-123 B$ & & $\mathrm{C}-1$ & \\
\hline Total geral & & & 180 & & & & & \\
\hline
\end{tabular}

arbóreas (pertencentes a 36 famílias botânicas), distribuídas conforme a densidade estimada de 806,4 indivíduos por hectare (CAP>15 cm) (TOMÉ et al. 1999). As árvores mais abundantes, freqüentes e dominantes (área basal), ou seja, que apresentam maior Índice de Valor de Importância (IVI), são o pau-d'álho Gallesia integrifolia (Phytolaccaceae), sangueiro Croton floribundus (Euphorbiaceae), paujacaré Piptadenia gonoacantha (Mimosaceae), branquilho-graúdo Sebastiania brasiliensis (Euphorbiaceae), cega-olho Pachystroma longifolium (Euphorbiaceae), canela-imbuia Nectandra megapotamica (Lauraceae), peroba Aspidosperma polyneuron (Apocynaceae), tapiá Alchornea glandulosa (Euphorbiaceae), cincho Sorocea bonplandii (Moraceae) e roseira Bougainvillea glabra (Nyctaginaceae) (TOMÉ et al. 1999).

Uma das manchas de banhado, formada após o represamento de um córrego, caracteriza-se pelo domínio da taboa Typha domingensis (Typhaceae) e a segunda, certamente de origem natural (banhado primário), pelo domínio da taboa e da conta-de-rosário Coix lacrymajobi (Poaceae), uma planta introduzida da Índia. Arbustos e arvoretas de várias espécies também acham-se presentes. Nos arredores do córrego que forma este banhado, ocorre uma diminuta área de floresta paludosa.

O P.E. está bastante alterado; houve retirada seletiva de madeira; algumas clareiras se formaram pela ação do vento; e há cerca de 30 anos, aproximadamente $20 \%$ da sua área foi afetada por um incêndio (Tomé et al. 1999). Tais impactos certamente propiciaram o alastramento de lianas e taquarais de Lasiacis sp. (Poaceae), que foram encontrados respectivamente em $92,8 \%$ e $57,6 \%$ da área do P.E. amostrada em estudos fitossociológicos (divulgado por Tomé e Vilhena no $4^{\circ}$ Simpósio Internacional Sobre Ecossistemas Florestais - FOREST 96, p. 11-13 do livro de resumos, Belo Horizonte, 1996; ToMÉ et al. 1999). Muitas árvores encontram-se completamente envoltas pelos cipós, o que dificulta o crescimento dos galhos e facilita a quebra dos mesmos devido ao excesso de peso. Nestes locais, o estrato superior não apresenta mais uma cobertura homogênea. As lianas em muitos pontos também revestem o solo, 
formando um "tapete" que aparentemente compromete o desenvolvimento do estrato inferior, o crescimento de plântulas e a rebrota de árvores cortadas. Os taquarais formam vastas manchas compactas, que também dificultam a regeneração da vegetação do interior da floresta (TOMÉ et al. 1999). Quanto a outros impactos, destaca-se a caça e a maciça retirada do palmito Euterpe edulis (Arecaceae) para a alimentação humana (observação pessoal).

Algumas aves foram libertadas no P.E. na ocasião da sua inauguração, a saber: macuco Tinamus solitarius (Vieillot, 1819), inhambu Crypturellus sp. (Tinamidae), jacupemba Penelope superciliaris e jacutinga Pipile jacutinga (Spix, 1825) (Cracidae) (divulgado com fotografias em um jornal local).

O B.M. (c. $23^{\circ} 11^{\prime} \mathrm{S}, 50^{\circ} 38^{\prime} \mathrm{W}$; c. $670 \mathrm{~m}$ s.n.m.), localizado no município de Cornélio Procópio, é uma área pública destinada à visitação administrada em parceria pelo Município e o Grupo Ecológico Vida Verde. Compõe-se por floresta primária alterada, além de vegetais exóticos ornamentais e é recortado por diversas estradas pavimentadas. É circundado por uma rodovia, por zonas cultivadas e em pequena porção pela cidade, distando em torno de $4 \mathrm{~km}$ do P.E. e apenas $375 \mathrm{~m}$ da M.S.P. No passado, todo o sub-bosque era cortado pela administração municipal, mas desde 1990 deixou-se a vegetação crescer (A.H.T. de Vilhena comunicação pessoal, 1998), exceto os cipós que ainda são cortados em quase toda a área. O dossel da floresta é homogêneo, mas o estrato intermediário é ralo, pois a regeneração do estrato inferior situa-se apenas entre aproximadamente 1 e $4 \mathrm{~m}$ de altura.

$\mathrm{Na}$ altura da floresta e aparentemente na composição de espécies, recorda ao descrito para o P.E., mas destaca-se a ausência de palmitos adultos, a grande quantidade de paus-jacarés e a presença da palmeira macaúba Acrocomia aculeata (Arecaceae), espécie do Brasil central que tem seu limite austral de ocorrência no extremo norte e noroeste do Paraná (observação pessoal; vide LORENZI et al. 1996).

A M.S.P. (c. $23^{\circ} 11^{\prime}$ S, $50^{\circ} 37^{\prime} \mathrm{W}$; c. $600 \mathrm{~m}$ s.n.m), situada no município de Cornélio Procópio, é uma área privada que encontra-se em razoável a bom estado de conservação. Forte degradação ocorreu em meados de 1997, com a derrubada de várias perobas e a conseqüente abertura de estradas e clareiras para a retirada de seus troncos. No seu entorno ocorrem plantações, pastagens e um açude parcialmente margeado por banhado.

\section{RESULTADOS}

Registrou-se 180 espécies, sendo 166 no P.E., 84 no B.M. e 99 na M.S.P., área que foi pouquíssimo amostrada. As espécies encontradas por período totalizaram 123 em fevereiro, $132 \mathrm{em}$ julho e $138 \mathrm{em}$ outubro, enquanto que a soma geral acumulou 40 e 17 espécies nos últimos períodos, respectivamente. Oitenta espécies foram registradas nos três períodos (44,4\%), 53 em dois $(29,4 \%)$ e 47 em um só $(26,1 \%)$. Algumas espécies registradas são consideradas ameaçadas de extinção (vide mais adiante), e 22 são endêmicas do Bioma Floresta Atlântica (Tab. I; vide "discussão"). Nenhuma daquelas espécies soltas no P.E. foi observada.

Com freqüência de ocorrência acima de $75 \%$, registrou-se 21 espécies no P.E., sete no B.M. e cinco na M.S.P., sendo a asa-branca Columba picazuro a única 
que apresentou esta percentagem nas três áreas (Tab. I). Várias aves freqüentes no P.E. não foram encontradas no B.M., a saber: pica-pau-anão-de-coleira, benedito Melanerpes flavifrons, chocão-carijó Hypoedaleus guttatus, borralhara Mackenziaena severa, papa-taoca Pyriglena leucoptera, arapaçu-rajado Lepidocolaptes fuscus e cabeçudo Leptopogon amaurocephalus. O tuju Lurocalis semitorquatus, o chororozinho-de-asa-vermelha Herpsilochmus rufimarginatus e o sabiá-barranco Turdus leucomelas foram nitidamente mais freqüentes no B.M. do que no P.E.

Não obstante a reduzida área do B.M., cinco espécies foram registradas apenas neste fragmento: gavião-bombachinha Harpagus diodon, jacuguaçu Penelope obscura, tesourão Eupetomena macroura, poiaeiro-do-sul Phyllomyias burmeisteri e pimentão Pitylus fuliginosus.

Embora não tenha sido efetuado senso de espécies, ao que parece as aves mais numerosas nos remanescentes são a choquinha-lisa Dysithamnus mentalis, o pula-pula Basileuterus culicivorus e o tiê-de-topete Trichothraupis melanops.

Registrou-se uma espécie migratória, o sabiá-ferreiro Turdus subalaris, mas salienta-se que o papa-moscas-cinzento Contopus cinereus também pode ser migrante (vide WIILIS 1979: 13). Ainda registrou-se aves que nidificam na região e depois migram no período invernal (residentes migratórias), que são pelo menos o sovi Ictinia plumbea, andorinhão-do-temporal Chaetura andrei, irrê Myiarchus swainsoni, bentevi-rajado Myiodynastes maculatus, bentevi-pirata Legatus leucophaius, peitica Empidonomus varius, tesourinha Tyrannus savana, suiriri T. melancholicus e a juruviara Vireo chivi. Devido ao pouco conhecimento sobre muitas aves no norte do Paraná, não se pode assegurar, no momento, se outras espécies apresentam similar sazonalidade.

A seguir, comenta-se as ocorrências relevantes para a região:

Urubu-rei Sarcoramphus papa. Um adulto observado voando sobre a floresta no P.E. (município de Santa Mariana) em 17/II. É uma espécie pouco registrada no Paraná.

Gavião-de-cabeça-cinza Leptodon cayanensis. O registro da espécie se baseia nos restos de um indivíduo, provavelmente ninhego, encontrado no P.E. (município de Santa Mariana) em fevereiro.

Gavião-bombachinha Harpagus diodon. Um indivíduo observado no B.M. em 16/II. É considerada ameaçada de extinção no Paraná (Lei n 11.067 , de 17/II/95; vide PARANÁ/SEMA 1995).

Gavião-de-cauda-curta Buteo brachyurus. Um indivíduo visto voando sobre a floresta no P.E. (municípios de Santa Mariana e Cornélio Procópio) em 17/II, 06 e 08/VII e em 08/X. Conta-se com poucas ocorrências publicadas desta espécie para o Paraná.

Jacuguaçu Penelope obscura. Um indivíduo visto no B.M. junto com um grupo de jacupembas, em 19/II e 08/VII. Esta ave tem sido escassamente registrada no norte do Paraná. A espécie possui duas subespécies no Brasil, das quais $P$. $O$. bronzina Hellmayr, 1914, que é a forma com ocorrência na área (análise por distribuição, pois não houve coleta), é considerada ameaçada de extinção no país (BERNARDES et al. 1990). 
Saracurinha-da-mata Amaurolimnas concolor. Um indivíduo ouvido no P.E. (município de Cornélio Procópio) ao entardecer em um brejo de conta-de-rosário, próximo de uma área de floresta paludosa, em 08/X (foi gravado). É o primeiro registro para o interior do Estado. Ademais, é conhecida de algumas localidades no litoral, a maioria inéditas.

Seriema Cariama cristata. Um indivíduo ouvido em uma área de agricultura no entorno do P.E. (município de Santa Mariana), em 06/VII. A sua ocorrência na região certamente se deve a uma recente colonização, possibilitada pela substituição das florestas por zonas abertas de pastagem e agricultura. Conta-se com mais quatro localidades de registros para os arredores: Fazenda Palmeira $\left(23^{\circ} 05^{\prime} \mathrm{S}, 50^{\circ} 32^{\prime} \mathrm{W}\right)$ e Fazenda Figueira (230' $\left.\mathrm{S}, 50^{\circ} 32^{\prime} \mathrm{W}\right)$, no município de Santa Mariana, e Fazenda Tamonas ( $22^{\circ} 59^{\prime}$ S, $50^{\circ} 43^{\prime} \mathrm{W}$ ) e Sítio São Geraldo ( $\left.23^{\circ} 04^{\prime} \mathrm{S}, 50^{\circ} 48^{\prime} \mathrm{W}\right)$, no município de Leópolis, nas quais a espécie tem sido observada desde 1996 (C. Gamerschlag e M. Boye comunicação pessoal, 1998). Em I/98, foi visto no Sítio São Geraldo um ninho em um arbusto no meio de uma pastagem contendo três filhotes, dos quais dois foram predados por um gavião e o terceiro morreu dias após na residência dos moradores que o capturaram (M. Boye comunicação pessoal, 1998). É considerada ameaçada de extinção no Paraná (Lei n ${ }^{\circ} 11.067$, de 17/II/95).

Cuiú-cuiú Pionopsitta pileata. Um indivíduo ouvido no P.E. (município de Cornélio Procópio) em 08/VII.

Papagaio-de-peito-roxo Amazona vinacea. Um indivíduo ouvido em um grupo de maitacas Pionus maximiliani no P.E. (município de Santa Mariana), em 20/II. Ainda se teve a impressão de ouvir-se um indivíduo na M.S.P., em 09/VII. É considerada ameaçada de extinção a nível nacional (BERNARDES et al. 1990) e global (Collar et al. 1992, 1994).

Murucututu Pulsatrix koeniswaldiana. Um indivíduo ouvido na M.S.P. (19/II e 10/X) e no B.M. (09/X) (a espécie foi gravada). Nesta reserva comprovou-se a nidificação da espécie, pois um ninhego debilitado foi encontrado em XII/96 (M. Boye comunicação pessoal, 1998; identificação por fotografia).

Coruja-preta Ciccaba huhula. Uma fêmea morreu ao se chocar com a residência da sede do P.E. (Santa Mariana), que situa-se na borda da floresta, em 05/VII/98 (J. Galdino comunicação pessoal, 1998). O exemplar, que possuía um morcego fêmea e seu filhote como conteúdo estomacal (J. Galdino comunicação pessoal), foi preparado em "postura-natural" e incorporado na coleção da Faculdade Estadual de Filosofia, Ciência e Letras de Cornélio Procópio. Este é o segundo registro da espécie para o Estado. O primeiro foi obtido com a observação de um indivíduo no Parque Estadual de Vila Rica do Espírito Santo (23⒌'S, $51^{\circ} 57^{\prime} \mathrm{W}$ ), município de Fênix, em VI/89 (SCHERER-NeTO \& STRAubE 1995). É considerada ameaçada de extinção no Paraná (Lei n 11.067 , de 17/II/95).

Tesourão Eupetomena macroura. Um indivíduo observado no B.M. em 09/X. É pouco conhecida no Paraná.

Araçari-banana Baillonius bailloni. Registro no P.E. (município de Santa Mariana) de quatro indivíduos alimentando-se dos frutos de uma Lauraceae, em 06/VII, e vários voando e vocalizando ativamente em 08 e 10/X (a espécie foi gravada). Apresenta poucas ocorrências no Estado. 
Pica-pau-rei Campephilus robustus. Uma fêmea vista no P.E. (município de Santa Mariana) em 07/VII. É espécie considerada ameaçada de extinção no Brasil (BERNARDES et al. 1990).

Poiaeiro-do-sul Phyllomyias burmeisteri. Um indivíduo observado no B.M. em 09/VII e 07/X. A espécie foi gravada e o registro sonoro foi submetido a Bret M. Whitney, que confirmou a identificação. É uma espécie pouco conhecida no Paraná.

Teque-teque Todirostrum poliocephalum. Vários registros no interior da floresta nas três campanhas no P.E. (municípios de Santa Mariana e Cornélio Procópio), um indivíduo ouvido na M.S.P. em 10/X, e um indivíduo ouvido no B.M. em 09/X, marcando o primeiro caso de sintopia com o relógio $T$. cinereum no Paraná (a espécie foi gravada). Até então, era conhecido no Paraná apenas da costa atlântica, uma vez que o registro de ANJOS \& SEgER (1988) para o noroeste do Estado resultou de um erro de identificação (STRAUBE et al. 1996). A afirmação de STRAUBE \& BORNSCHEIN (1995) de que esta espécie seria no Paraná restrita à planície litorânea é improcedente, pois era esperado registrá-la no interior do Estado, uma vez que conta com uma coleta no oeste de São Paulo (PINTO 1944: 222). O autor sênior possui dois registros adicionais inéditos da espécie para o planalto paranaense, a saber: um indivíduo observado em um arbusto na beira do rio Capivari, Fazenda Capivari $\left(25^{\circ} 12^{\prime} \mathrm{S}, 48^{\circ} 57^{\prime} \mathrm{W}\right)$, município de Campina Grande do Sul, em 27/XI/89; um indivíduo ouvido na floresta ciliar da foz do rio Taquara, Fazenda Sertãozinho ( $\left.23^{\circ} 31^{\prime} \mathrm{S}, 50^{\circ} 58^{\prime} \mathrm{W}\right)$, município de Londrina, em 07/II/96.

Relógio $T$. cinereum. Registrado em arvoretas parcialmente isoladas na borda da floresta no P.E (07/VII; 08 e 10/X) (municípios de Santa Mariana e Cornélio Procópio) e na M.S.P (17/II), e no ambiente florestal no B.M. (15, 17 e 19/II; 07/X). É uma ave comum do norte ao oeste do Paraná, região que marca o seu limite austral de distribuição no Brasil.

Sabiá-ferreiro Turdus subalaris. Um indivíduo ouvido no P.E. (município de Santa Mariana) de 08 a 10/X (a espécie foi gravada). Esta espécie é comum nas florestas de araucária do Sul do Brasil (Floresta Ombrófila Mista sensu Veloso et al. 1991), de onde migra após reproduzir-se, devendo aparecer na região de estudo apenas de passagem.

Canário-do-mato Basileuterus flaveolus. Um indivíduo registrado no P.E. (município de Santa Mariana) em 19/II (foi gravado e fotografado). Apenas recentemente esta espécie tornou-se conhecida para o Paraná: em 1993 foi observada freqüentemente em remanescentes florestais do médio rio Paranapanema, dos quais um no município de Andirá ( $\left.23^{\circ} 04^{\prime} \mathrm{S}, 50^{\circ} 14^{\prime} \mathrm{W}\right)$, de onde o Museu Nacional (Rio de Janeiro) possui um espécime coletado em VII/93 (divulgado por Raposo e outros no IV Congresso Brasileiro de Ornitologia, p. 49 do livro de resumos, Recife, 1994).

Pipira-vermelha Ramphocelus carbo. Cinco indivíduos vistos na floresta adjacente a um brejo em 08/VII no P.E. (município de Cornélio Procópio). O seu limite austral de distribuição no Brasil é o Paraná, onde é comum na região noroeste às margens do rio Paraná e aparentemente incomum no norte, pois conta com poucos registros. 
Cigarra-do-coqueiro Tiaris fuliginosa. Um indivíduo ouvido no P.E. (08/VII, 08 e 10/X) (municípios de Santa Mariana e Cornélio Procópio) e na M.S.P. (16/II). Esta espécie possui poucas localidades de registro no Paraná (vide BoRNsCHEIN \& REINERT 1996; ANJOS \& SCHUCHMANN 1997).

Cardeal-do-banhado Amblyramphus holosericeus. Um sub-adulto, provavelmente errante, observado em 10/X no P.E. (município de Santa Mariana) em um banhado secundário dominado pela taboa (foi gravado). Este é o primeiro registro publicado para o Paraná. Ademais, os autores efetuaram algumas observações em uma localidade no Parque Nacional de Ilha Grande, no oeste do Estado.

\section{DISCUSSÃO}

Mesmo sendo um trabalho preliminar, considerou-se baixo o número de aves inventariadas no P.E., o que se acredita ser devido ao estado de forte degradação em que ele se encontra. A título comparativo, foram registradas sete espécies no B.M. que não foram vistas no P.E. (vide resultados), e na M.S.P. outras três inéditas (Tab. I). No Parque Estadual Mata dos Godoy $\left(23^{\circ} 27^{\prime} \mathrm{S}, 51^{\circ} 15^{\prime} \mathrm{W}\right)$, que situa-se próximo e possui semelhante característica, mas tamanho menor, foram registradas 277 espécies (ANJOS et al. 1997), algumas de ocorrência duvidosa, e.g. periquito-rei Aratinga aurea (Gmelin, 1789) (Psittacidae), surucuá-grande-de-barriga-dourada Trogon viridis Linnaeus, 1766 (Trogonidae) e capitão-de-saíra Attila rufus (Vieillot, 1819) (Tyrannidae). Quanto ao número de aves daquele parque, ressalta-se que há discrepância: na listagem de ANJos et al. (1997) constam 277 espécies, mas na página 156 indica-se a soma de 273 espécies, e na listagem de ANJOS \& SCHUCHMANN (1997) constam para o mesmo local 274 espécies.

Por causa do reduzido tamanho do B.M., obviamente esperava-se registrar um menor número de espécies do que no P.E. Todavia, atendo-se à pequena área e à intensa visitação que sofre, o B.M. revelou-se rico em espécies. No entanto, muitas delas certamente se acham presentes devido à proximidade com a M.S.P. A curta distância que separa estas duas áreas $(375 \mathrm{~m})$, não é obstáculo para o trânsito de aves com maior potencial de vôo, como por exemplo espécies de Columbidae e Psittacidae, que freqüentemente foram vistas deslocando-se entre os dois fragmentos. Levando em conta que o B.M. era até há pouco tempo desprovido de sub-bosque, supõem-se que algumas aves não subsistiram naquela condição e passaram a ocorrer somente após a sua regeneração, como o chupa-dente Conopophaga lineata e o miudinho Myiornis auricularis. Isto implicaria que estas espécies, de pequeno potencial de vôo, tem alguma capacidade de dispersão por áreas desmatadas.

A ornitofauna florestal registrada revelou alguns elementos estranhos à Floresta Estacional Semidecidual do Paraná. São estes a saracurinha-da-mata (ela foi vista em um banhado mas ao lado da floresta, seu hábitat característico) e o teque-teque, novos para a região, e o jacuguaçu, coruja-preta, beija-flor-de-peitoazul Amazilia lactea, sabiá-ferreiro, canário-do-mato e pipira-vermelha, pouco habituais nos inventários. A ocorrência do jacuguaçu e jacupemba em sintopia é fato interessante e não constatado no interior de São Paulo (GUIX 1997). 
Alguns dos registros apresentados representam novidades para a ornitofauna da bacia hidrográfica do rio Tibagi, conforme dados da região em ANJOS \& SchuchmanN (1997) e Anjos et al. (1997). Das localidades citadas neste estudo, pertence àquela bacia uma parte do B.M. (o resto na do rio Paranapanema), um dos locais de registro da seriema (Sítio São Geraldo), e um dos locais adicionais do teque-teque (Fazenda Sertãozinho). As novidades são as ocorrências do jacuguaçu, seriema e limpa-folha-ocrácea Philydor lichtensteini para o baixo rio Tibagi e do teque-teque para a bacia. A presença das três primeiras na região em questão não concorda com os padrões de distribuição que ANJOS \& SCHUCHMANN (1997) thes atribuíram na bacia. Uma vez que outras inúmeras observações pessoais na bacia hidrográfica do rio Tibagi também provaram igual discordância, parece que os 15 padrões de distribuição das aves criados por aqueles autores melhor representem zonas de registro, ao invés de padrões propriamente ditos.

Por serem as áreas estudadas ilhas de floresta em meio à paisagens de origem antrópica, era esperável encontrar algumas espécies avançando sc bre ambientes atípicos, como por exemplo a florestal tiriba Pyrrhura frontalis em uma árvore no meio de uma pastagem, e o urbano pardal Passer domesticus dentro da floresta ao lado de uma choquinha-lisa com seu filhote (vide ambiente na tabela I). A maioria das aves características de paisagens abertas observadas no ambiente florestal, foram registradas na borda da floresta.

As áreas abertas de origem antrópica representadas pelas zonas de agricultura e pastagem, compõem-se por aves colonizadoras. Esta colonização foi efetuada por dezenas de espécies que certamente já habitavam a região (colonização de curta distância; espécies autóctones), e por espécies que supostamente chegaram de outras partes (colonização de longa distância; espécies alóctones). Da região, colonizaram aves que são comuns na floresta como a juriti Leptotila verreauxi, nos banhados como o anu-preto Crotophaga ani (vide "banhado primário" mais adiante), e nos ambientes semelhantes à capoeiras, ocorrentes por exemplo em clareiras ou em banhados em estágio avançado de sucessão vegetacional, onde abundam arbustos e arvoretas (vide BORNSCHEIN \& REINERT 1999), como a rola Columbina talpacoti e o bentevi Pitangus sulphuratus. De outras partes, colonizaram principalmente espécies que habitavam as distantes paisagens campestres naturais. Julga-se como exemplos deste caso a codorna-comum Nothura maculosa, caracará Polyborus plancus, seriema (vide comentário nos resultados), quero-quero Vanellus chilensis, anu-branco Guira guira, coruja-buraqueira Speotyto cunicularia, pica-pau-do-campo Colaptes campestris, birro, choca-de-chapéu-vermelho Thamnophilus ruficapillus, joão-de-barro Furnarius rufus, tesourinha, sabiá-do-campo Mimus saturninus, caminheiro-zumbidor Anthus lutescens, tico-tico Zonotrichia capensis, tico-ticodo-campo Ammodramus humeralis e a polícia-inglesa Leistes superciliaris. De outra parte ainda colonizou as zonas de agricultura e pastagem a garça-vaqueira Bubulcus ibis, que não se enquadra na situação anterior por ter se dispersado pelas Américas vindo da África.

Colonização também ocorreu nas áreas abertas de origem antrópica representadas pelos açudes e banhados secundários. As cinco espécies registradas nos açudes (ambiente aquático; e.g. mergulhão-pequeno Tachybaptus dominicus e 
andorinha-do-rio Tachycineta albiventer; Tab. I), possivelmente vieram dos rios maiores existentes na região, como o Paranapanema e Tibagi (colonização de média distância; espécies autóctones da macro região). As aves dos banhados secundários certamente provieram da região (colonização de curta distância), dada a existência de ao menos uma mancha de banhado com origem natural na área de estudo (banhado primário; exceção é o errante cardeal-do-banhado - vide "resultados"). Embora o mapa fitogeográfico do Paraná não assinale a ocorrência de banhados no norte do Estado (MAACK 1950; vide "caracterização da região de estudo"), isto certamente se deveu ao fato de serem pouco representativos e de difícil representação na escala trabalhada.

Uma espécie registrada, a asa-branca, é colonizadora tanto de florestas quanto de áreas abertas. Esta ave chegou ao Paraná provavelmente expandindo a sua população austral (colonização de longa distância), outrora isolada, e atualmente já é comum em quase todo Estado, especialmente nas regiões centro-norte e oeste.

Há ainđa um rol de espécies características de áreas abertas e/ou de florestas mais ralas, que podem ou não ser nativas da região, o que mais estudos talvez esclareça. Estas aves ou já ocorriam, por exemplo, nos brejos primários, zonas arbustivas naturais e/ou na beira de rios da região, ou a colonizaram dispersando-se através de ambientes antrópicos que elas usualmente habitam, como pastagens, capoeiras, pomares e/ou áreas urbanas. Entre algumas das espécies que se considera deste grupo, tem-se a choca-barrada Thamnophilus doliatus, relógio, alegrinho Serpophaga subcristata, filipe Myiophobus fasciatus, bentevi-do-gado Machetornis rixosus, as andorinhas (exceto a andorinha-do-rio, comentada anteriormente) e a corruíra Troglodytes aedon. Particularmente quanto às duas primeiras, suspeita-se que no Paraná elas habitavam originalmente ambientes ciliares, rejuvenescidos pela dinâmica dos rios, e se expandiram além desta fronteira após a transformação da paisagem pelo homem, atingindo inclusive florestas distantes de rios, mas restritas às bordas (colonização de curta ou média distância).

A presença do relógio no rio Ivaí, na porção centro-norte do Paraná, em 1922 (SZTOLCMAN 1926: 160), reforça o padrão de colonização suposto para esta espécie. $\mathrm{Na}$ época deste registro, a região se achava praticamente intacta e a possibilidade da espécie tê-la colonizado parece remota, haja visto que as únicas frentes de antropização não seriam favoráveis a isso, a sul-sudeste pela inexistência da ave na região, e a nordeste por uma questão cronológica. A ocupação humana iniciada nesta região no princípio do século XX, atingiu porções mais centrais do Estado por volta da década de 30 , e como não é esperado que a espécie empreenda um processo de colonização simultâneo com desmatamentos, parece improvável ter havido tempo suficiente para permitir a sua chegada na região centro-norte do Estado em 1922. Seria plausível, então, considerá-la como nativa de ambientes ciliares no rio Ivaí. Assumindo-se isso, é razoável assumir o mesmo pelo menos para a região do vale do rio Paraná, no noroeste do Estado, onde, entretanto, a espécie não foi registrada nas primeiras pesquisas ali efetuadas (STRAUBE \& BORNSCHEIN 1995). No entanto, é provável que ela apenas não tenha sido coletada, pois mesmo espécies florestais, que aparentemente foram melhor inventariadas na região do que aves palustres e ripárias, ainda continuam sendo acrescentadas à ornitofauna local (informação pessoal). 
Assim como a interferência do homem na paisagem natural possibilitou que muitas espécies colonizassem novas áreas, a destruição das florestas causou extinção local de aves. Hoje estão desaparecidas do norte do Paraná pelo menos o gavião-real Harpia harpyja (Linnaeus, 1758) (Accipitridae) e a arara-vermelhagrande Ara chloroptera Gray, 1859 (Psittacidae). O gavião-real foi registrado na região de Londrina no início da década de 30 (SCHERER-NETO \& STRAUBE 1995), e a arara-vermelha-grande era comum na área de estudo até meados da mesma década, conforme informação de um antigo caçador local. Algumas espécies ameaçadas, como o macuco, jacutinga, maracanã-do-buriti Propyrrhura maracana (Vieillot, 1816) e a jandaia Aratinga solstitialis (Linnaeus, 1766) (Psittacidae), não foram inventariadas mas talvez o sejam com a continuidade dos estudos, pois elas ainda podem ser encontradas em certos locais do norte paranaense.

Quanto à lista de aves endêmicas do Bioma Floresta Atlântica (Tab. I), que inclui as florestas de grande parte da costa brasileira e de parte do interior do país até o sul de Goiás, leste do Mato Grosso do Sul, leste do Paraguai e nordeste da Argentina, como também os ambientes não florestais incluídos nesta região, adotou-se com reservas PARKER et al. (1996). Como algumas daquelas espécies são residentes ou supostamente residentes em outras regiões, se entende isto como motivo para desconsiderá-las endêmicas. Estas espécies são as seguintes: surucuáde-peito-azul Trogon surrucura, juruva Baryphthengus ruficapillus, benedito, chupa-dente, vira-folhas Sclerurus scansor, limpa-folha-ocrácea, barranqueiro-deolho-branco Automolus leucophthalmus, tiriba, pica-pauzinho-verde-carijó Veniliornis spilogaster e tiê-preto Tachyphonus coronatus. As cinco primeiras foram registradas no norte de Goiás (região do Parque Nacional da Chapada dos Veadeiros; registro inédito dos autores), sendo que o chupa-dente também no Mato Grosso (SIlva \& ONIKI 1988; CINTRA \& YAMASHITA 1990), e as duas seguintes no Distrito Federal (ANTAS 1995). A tiriba ocorre no norte da Argentina e no Uruguai (FoRSHAw 1977), o pica-pauzinho-verde-carijó no Uruguai (SICK 1997), e o tiê-preto em ampla região do centro-sul do Paraguai (ISLER \& ISLER 1987). BROOKS et al. (1999) consideraram esta problemática, assinalando várias espécies que julgaram não estritamente endêmicas, posição que, de acordo com informações que os autores dispõem, é corroborada em alguns casos mas não em outros.

Outra exceção na relação de endemismos do Bioma Floresta Atlântica é o rabo-branco-miúdo Phaethornis squalidus, que PARKER et al. (1996) considerou incluir uma subespécie amazônica e que SICK (1997) reputou como espécie independente, motivo pelo qual foi tratada como endêmica.

\section{Conservação}

Primeiramente, é importante destacar que "a amplitude da devastação das matas efetuada pelo homem no Estado do Paraná escapa a qualquer descrição" (MAACK 1963). Considerando ainda que até nos dias de hoje a perda de ambientes continua sendo o maior problema para a conservação das aves no Paraná, não é de surpreender que uma área com apenas 832,5 ha seja o maior remanescente florestal do norte do Estado. 
Neste contexto onde milhares de hectares jazem quase esterilizados, a existência dos remanescentes florestais estudados por si só reveste-os de grande importância para a conservação. A presença de espécies endêmicas do Bioma Floresta Atlântica e a existência de algumas consideradas ameaçadas de extinção (vide adiante), reforçam esta importância.

As aves florestais ameaçadas compõem-se por cinco espécies (exclui-se aqui a seriema), das quais duas de acordo com a lista paranaense (gavião-bombachinha, coruja-preta), duas conforme a lista brasileira (jacuguaçu, pica-pau-rei) e uma conforme a lista brasileira e mundial (papagaio-de-peito-roxo) (vide resultados). A presença deste papagaio é sem dúvida a mais notória, mas até o momento não se sabe se existe uma população viável no local.

A lei paranaense que criou a lista de fauna ameaçada de extinção, estabelece ainda que as espécies "que apresentam o Estado do Paraná como seu limite de distribuição geográfica", também devem ser consideradas ameaçadas. Isto se aplica para a choca-barrada, relógio, canário-do-mato, pipira-vermelha e para o tico-ticodo-mato-de-bico-amarelo Arremon flavirostris, que possuem o Paraná como limite sul de suas distribuições no Brasil.

O canário-do-mato foi listado para Santa Catarina (SICK et al. 1981; BEGE \& MARTERER 1991; ROSÁRIO 1996), mas a sua presença no Estado necessita confirmação. De acordo com a literatura corrente, a saracurinha-da-mata teria no Paraná o seu limite austral de distribuição, mas existe uma ocorrência antiga para "Santa Catarina" (IHERING 1902) e um registro inédito recente (1999) dos autores para o litoral norte deste Estado (Ilha de São Francisco).

Recomenda-se a implantação de um programa que vise aumentar o número de áreas protegidas e unir os fragmentos florestais. Como resultado de esforços institucionais, dentro em breve deverão ser criados vários mecanismos de vantagem aos proprietários que possuem áreas florestais, o que facilitará em muito a implantação de propostas como essa, mas por agora vislumbra-se somente dois aspectos auxiliadores. Com a criação de reservas, o Município sede receberá mensalmente um percentual dos recursos financeiros captados pelo Projeto do ICMS Ecológico no Paraná (Lei Estadual Complementar n 59/91, regulamentada pelos Decretos Estaduais n ${ }^{\circ} 974 / 91$ e 2791/96) (vide LOUREIRO 1997). O outro aspecto diz respeito à Reserva Florestal Legal de $20 \%$ das propriedades rurais, exigida no Código Florestal Brasileiro (Lei Federal $n^{\circ} 4.771$, de 15/IX/65). Por norma legal recente (decreto 387, de 03/III/1999, regulamentado pela portaria 100/99 do Instituto Ambiental do Paraná - IAP/GP, de 26/VII/1999), se permite no Paraná que os proprietários inadimplentes atendam a exigência da reserva legal adquirindo terras descontínuas. Com isto, é possível que se comprem locais florestados, opção muito mais favorável do que o isolamento de $20 \%$ ou menos de uma propriedade, muitas vezes cultivado, para que este inicie o lento proceșso de regeneração, particularmente moroso quando o solo se encontra exaurido, desprovido de um banco de sementes e distante de remanescentes de vegetação nativa. Obviamente que esta proposta se aplicaria a florestas que excedem ao exigido como Reserva Florestal Legal, o que, aliás, pode desimpedir o uso destas áreas. Também seria possível orientar a compra de locais desmatados entre fragmentos florestais, que após 
regenerados os conectariam servindo como corredores de fauna. Em todos os casos, é importante que o Poder Público interfira na escolha de áreas, e que se considere ambientes quanto mais similares possíveis.

A aquisição de áreas descontínuas como reserva legal no contexto da região estudada permitiria, envolvendo somente uma diminuta porção de terras, conectar o B.M com a M.S.P., separados por apenas $375 \mathrm{~m}$. Outra possibilidade seria a proteção da fração da M.S.P. que excede os $20 \%$ de Reserva Florestal Legal (A.H.T. de Vilhena comunicação pessoal, 1998). Com estas ações se garantiria melhores condições para a manutenção da biota local, pois a supressão da cobertura florestal provoca perda de espécies, e em fragmentos de floresta originados pela ação do homem o empobrecimento ocorre continuamente (SICK 1997).

\section{Propostas de manejo}

A seguir, são sugeridas algumas medidas para o manejo do P.E.

Realizar o contínuo corte dos cipós nos locais onde eles formam densos povoamentos. Em uma parte de um fragmento florestal no interior de São Paulo com baixa densidade de árvores, constatou-se ausência de regeneração arbórea devido ao domínio de cipós (TABANEZ et al. 1996). Se acrescentou ainda que o controle de lianas é efetivo na sucessão da vegetação, e que não deve representar risco de extinção local de cipós, pois as espécies que causam danos aparentemente são pioneiras e mais agressivas, sugerindo que o manejo apenas restringiria $o$ desenvolvimento destas poucas espécies (divulgado por Tabanez e outros no $4^{\circ}$ Simpósio Internacional Sobre Ecossistemas Florestais - FOREST 96, p. 98-99 do livro de resumos, Belo Horizonte, 1996).

Promover o adensamento da vegetação com plantio de espécies nativas, enfatizando aquelas cuja raridade se deve à extração seletiva (e.g. palmito).

Fiscalizar o P.E. contra a caça e o fogo, neste caso particularmente quando são realizadas queimadas nos canaviais do entorno. Quase toda a borda do P.E. apresenta o africano capim-colonião Panicum maximum (Poaceae), que por ser um excelente combustível aumenta o risco de incêndios florestais. As queimadas, não obstante representem grave impacto na maioria dos ecossistemas brasileiros, tem sido insuficientemente combatidas e discutidas no país. A título ilustrativo, somente no Paraná durante 1999, ocorreram vários incêndios de pequena a grande proporção em inúmeras unidades de conservação do Estado, como o Parque Nacional de Ilha Grande, Parque Nacional de Superagüi e Parque Estadual de Vila Velha.

Impedir o trânsito de animais domésticos, cujo impacto ao ambiente muitas vezes é subestimado. Cães, por exemplo, solitários ou organizados em matilhas, matam até animais de maior porte como veados.

Não realizar solturas de animais silvestres sem prévios estudos específicos.

Desaconselha-se o represamento de um córrego para formar um açude com fins recreativos, conforme foi aventado, devido a possibilidade de perda da floresta paludosa e de um trecho significativo de banhado. Caso ocorram novas construções para a infra-estrutura do P.E., desaconselha-se o uso de grandes vidraças, porque refletem a vegetação circundante confundindo aves que voam de encontro ao vidro, chegando a morrer pelo choque. No Parque Estadual do Palmito, no litoral do Paraná, em uma ocasião contou-se 40 aves mortas ao lado das vidraças de uma construção. 
Para o manejo do B.M., propõem-se o corte gradual no fornecimento de alimento aos mamíferos silvestres [e.g. quati Nasua nasua (Linnaeus, 1766), Procyonidae], o afastamento de animais domésticos, o adensamento do palmito, a continuidade no desbaste de cipós e a perpetuação da regeneração do estrato inferior da floresta.

\begin{abstract}
AGRADECIMENTOS. O Grupo Ecológico Vida Verde patrocinou o projeto, com recursos da Deutsche Gesellschaft für Technische Zusammenarbeit (GTZ). Seus integrantes ofereceram alojamento, auxilio nos trabalhos de campo, informações relevantes, companhia e amizade, a saber: Rudiger e Margid Boye, Astolfo H.T. de Vilhena, Norbert e Cornélia Gamerschlag e Maria Vitória D.F. Tomé. O Instituto Ambiental do Paraná (IAP) forneceu autorização para pesquisa no P.E. e as fotos aéreas. João Galdino cedeu o registro da coruja-preta. Fernando Pacheco, Mauro Pichorim, Carlos Firkowski, Euclides (Tom) e Gislaine C. Grando, Rudiger e Margid Boye e um revisor anônimo leram criticamente o manuscrito. Dimas Pioli traduziu o resumo. Tereza Urban apresentou sugestões e forneceu embasamento na questão da Reserva Florestal Legal. Ainda agradecemos ao responsável pela M.S.P., que autorizou nosso acesso a esta propriedade.
\end{abstract}

\title{
REFERÊNCIAS BIBLIOGRÁFICAS
}

Anjos, L. DOS \& A.R.J. FerReira. 1998. Registros de campo de Hylocharis sapphirina e H. cyanus na região de Londrina, norte do Estado do Paraná, sul do Brasil (Trochiliformes: Trochilidae). Ararajuba 6 (1): 51 .

Anjos, L. DOS \& K.L. SCHUCHMANN. 1997. Biogeographical affinities of the avifauna of the Tibagi river basin, Parana drainage system, southern Brazil. Ecotropica 3 (1): 43-66.

AnJos, L. DOS; K.L. SCHUChMANN \& R.A. BERNDT. 1997. Avifaunal composition, species richness, and status in the Tibagi River Basin, Parana State, southern Brazil. Ornitologia Neotropical 8 (2): 145-173,

Anjos, L. Dos \& C. SEger. 1988. Análise da distribuição das aves em um trecho do rio Paraná, divisa entre os Estados do Paraná e Mato Grosso do Sul. Arq. Biol. Tecnol., Curitiba, 31 (4): 603-612.

Antas, P.T.Z. 1995. Aves do Parque Nacional de Brasília. Brasília, Instituto Brasileiro do Meio Ambiente e dos Recursos Naturais Renováveis - IBAMA, 53p.

BEge, L.A. Do R. \& B.T.P. MARTERER. 1991. Conservação da avifauna na região sul do Estado de Santa Catarina - Brasil. Florianópolis, Fundação do Meio Ambiente - FATMA, 54p.

Bernardes, A.T.; A.B.M MAChAdo \& A.B. RylAnds. 1990. Fauna brasileira ameaçada de extinção. Belo Horizonte, Fundação Biodiversitas para a Conservação da Diversidade Biológica, $62 \mathrm{p}$.

Bornschein, M.R. \& B.L. Reinert. 1996. Novos registros de Tiaris fuliginosa (Emberizidae) no Paraguai e no sul do Brasil. Ararajuba 4 (2): 105-106.

1999. Banhados do litoral do Paraná: alguns aspectos sobre sua nomenclatura, ecologia e conservação. Cadernos do Litoral 2: 11-16.

BornsCiIEIN, M.R.; B.L. REINERT \& M. PiCHORIM. 1997. Notas sobre algumas aves novas ou pouco conhecidas no sul do Brasil. Ararajuba 5 (1): 53-59.

BRoOKS, T.; J. TOBIAS \& A. BALMFORD. 1999. Deforestation and bird extinctions in the Atlantic forest. Animal Conservation 2: 211-222.

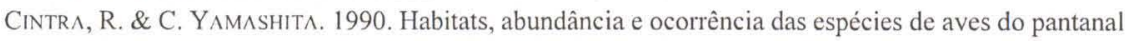
de Poconé, Mato Grosso, Brasil. Papéis Avulsos Zool., São Paulo, 37 (1): 1-21.

Collar, N.J.; L.A.P Gonzaga; N. Krabbe; A. Madroño Nieto; L.G. Naranjo; T.A. Parker \& D.C. WEGE. 1992. Threatened birds of the Americas: the ICBP/IUCN Red Data Book. Cambridge, International Council for Bird Preservation, $3^{\mathrm{a}}$ ed., 1150p.

Coll.ar, N.J.; M.J. Crosby \& A.J. STATTERSFiEI.D. 1994. Birds to watch 2: the world list of threatened 
birds. Cambridge, BirdLife International, 407p

Forshaw, J.M. 1977. Parrots of the World. Neptune, T.F.H. Publications, 584p.

FUNDAÇÃo sos MATA ATLÂNTICA. 1992a. Evolução dos remanescentes florestais e ecossistemas associados do domínio da Mata Atlântica. Estado do Paraná. Período: 1985 a 1990. São Paulo, Convênio Fundação SOS Mata Atlântica - INPE, 1 mapa, escala 1:1.700.000.

. 1992b. Evolução dos remanescentes florestais e ecossistemas associados do domínio da Mata Atlântica. Estado de Santa Catarina. Período: 1985 a 1990. São Paulo, Convênio Fundação SOS Mata Atlântica - INPE. I mapa, escala 1:1.700.000.

GuIX, J.C. 1997. Exclusão geográfica e ecológica de Penelope obscura, Penelope superciliaris e Pipile jacutinga (Galliformes, Cracidae) no estado de São Paulo. Ararajuba 5 (2): 195-202.

IAPAR. 1978. Cartas climáticas básicas do Estado do Paraná. Londrina, Fundação Instituto Agronômico do Paraná, 38p.

IHERING, H. vON. 1902. Contribuições para o conhecimento da ornithologia de São Paulo. Rev. Mus. Paul. 5: 261-329.

ISLER, M.L. \& P.R. ISLER. 1987. The tanagers: natural history, distribution, and identification. Washington, D.C., Smithsonian Institution Press, 404p.

Lorenzi, H.; H.M. de Souza; J.T. de Medeiros-Costa; L.S.C. de Cerqueira \& N. von Behr. 1996. Palmeiras no Brasil: exóticas e nativas. Nova Odessa, Editora Plantarum, 303p.

LOUREIRO, W. 1997. ICMS Ecológico - a contribuição conservacionista de uma política tributária, p. 500-517. In: Anais do Congresso Brasileiro de Unidades de Conservação, Curitiba, Instituto Ambiental do Paraná - IAP, Universidade Livre do Meio Ambiente - Unilivre e Rede Nacional Pró Unidades de Conservação, Vol. I.

MAACK, R. 1950. Mapa fitogeográfico do Estado do Paraná. Curitiba, Secretaria de Agricultura, Indústria e Comércio, 1 mapa, escala 1:750.000.

- 1963. O ritmo da devastação das matas no estado do Paraná, suas conseqüências e problemas de reflorestamento. Ciência e Cultura 15 (1): 25-33.

- 1981. Geografia física do Estado do Paraná. Curitiba, Livraria José Olympio Editora, $2^{3}$ ed., XLIII+450p.

Neto, F.L. 1995. Um híbrido entre Picumnus cirratus temminckii e P. albosquamatus guttifer (Piciformes: Picidae). Ararajuba 3: 68-69.

PARANA/SEMA. 1995. Lista vermelha de animais ameaçados de extinção no Estado do Paraná. Curitiba, Secretaria de Estado do Meio Ambiente - SEMA e Deutsche Gesellschaft für Technische Zusammenarbeit - GTZ, 176p.

Parker III, T.A; D.F. Stotz \& J.W. FitzPatrick. 1996. Ecological and distributional databases, p. 113-436. In: D.F Stotz; J.W. FitZPATRICK; T.A. PARker III \& D.K. Moskovits (Eds). Neotropical birds ecology and conservation. Chicago, Univ. Chicago Press, $\mathrm{XX}+478 \mathrm{p}$.

PINTO, O.M. DE O. 1938. Catálogo das aves do Brasil e lista dos exemplares que as representam no Museu Paulista. $1^{\text {a }}$ Parte: Aves não Passeriformes e Passeriformes não Oscines, excluída a família Tyrannidae e seguintes. Rev. Mus. Paulista 22: 1-566.

1944. Catálogo das aves do Brasil e lista dos exemplares na coleção do Departamento de Zoologia. $2^{a}$ Parte. Ordem Passeriformes (continuação): Superfamília Tyrannoidea e Subordem Passeres. São Paulo, Departamento de Zoologia, XI+700p.

1964 Ornitologia brasiliense. São Paulo, Departamento de Zoologia da Secretaria da Agricultura do Estado de São Paulo, Vol. 1, XIV+182p.

RoderJan, C.V.; Y.S. KunIYosulI \& F. GalvÃo. 1993. As regiões fitogeográficas do Estado do Paraná. Acta Forestalia Brasiliensis 1: 3-7.

RosÁrıO, L.A. DO. 1996. As aves em Santa Catarina: distribuição geográfica e meio ambiente. Florianópolis, Fundação do Meio Ambiente - FATMA, 326p.

RusCHI, A. 1986. Aves do Brasil, beija-flores. Rio de Janeiro, Expressão e Cultura, Vol. 5, p. 209-452. Scherer-Neto, P. \& F.C. Straube. 1995. Aves do Paraná (história, lista anotada e bibliografia). Campo Largo, Logos Press, V+79p. 
Sibi.Ey, C.G. \& B.L. Monroe-Jr. 1990. Distribution and taxonomy of birds of the world. New Haven, Yale Univ. Press, XXIV+1111p.

Sick, H. 1959. A invasão da América Latina pelo pardal, Passer domesticus Linnaeus 1758, com referência especial ao Brasil (Ploceidae, Aves). Bol. Mus. Nac., nova série zool. 207: 1-31.

-1960. Zur systematik und biologie der Bürzelstelzer (Rhinocryptidae), speziell Brasiliens. Jour. Ornitol. 101 (1/2): 141-174.

- 1985. Ornitologia brasileira: uma introdução. Brasília, Editora Universidade de Brasília, Vol. 1, XIX+480p.

-1997. Ornitologia brasileira. Rio de Janeiro, Editora Nova Fronteira, 862p.

Sick, H.; L.A. do Rosário \& T.R. DE A7evedo. 1981. Aves do Estado de Santa Catarina. Sellówia, sér. zool. 1: $1-51$.

SILVA, J.M.C. DA \& Y. ONIKı. 1988. Lista preliminar da avifauna da Estação Ecológica Serra das Araras, Mato Grosso, Brasil. Bol. Mus. Paraense Emílio Goeldi, sér. Zool., 4 (2): 123-143.

StEFFAn, K. VON. 1975. Vogelleben am Agua do Quati (Brasilien). Gefiedert Welt 98 (6): 102-104.

StRAUBE, F.C. \& M.R. BORNSCHEIN. 1995. New or noteworthy records of birds from northwestern Paraná and adjacent areas (Brazil). Bull. Brit. Ornitol. Club 115 (4): 219-225.

Straube, F.C.; M.R. Bornschein \& P. Scherer-Neto. 1996. Coletânea da avifauna da região noroeste do Estado do Paraná e áreas limítrofes (Brasil). Arq. Biol. Tecnol., Curitiba, 39 (1): 193-214.

Sztolcman, J. 1926. Étude des collections ornithologiques de Paraná. Ann. Zool. Mus. Pol. Hist. Nat. 5: 107-196.

TABANEZ, A.A.J.; V.M. VianA \& H.E.M. NASCimEnTo. 1996. Ecologia e recuperação de fragmentos florestais na mata Atlântica (II). Floresta 24 (1/2): 99-100.

Tome, M.V.D.F.; É. Miglioranza; A.H.T. de Vilhena \& É. DE P. FonseCA. 1999. Composição florística e fitossociológica do Parque Estadual Mata São Francisco. Rev. Inst. Florestal 11 (1): 12-23.

Veloso, H.P.; A.L.R. RANGel-Filho \& J.C.A. Lim^. 1991. Classificação da vegetação brasileira, adaptada a um sistema universal. Rio de Janeiro, Fundação Instituto Brasileiro de Geografia e Estatística - IBGE, 123p.

WestCotT, P.W. 1980. Descrição das aves encontradas na área urbana de Londrina-Paraná. Primeira parte - espécies não Passeriformes. Semina 6 (2): 59-66.

WILLIS, E.O. 1979. The composition of avian communities in remanescent woodlots in Southern Brazil. Papéis Avulsos Zool., São Paulo, 33 (1): 1-25.

WORKSHOP - M^T^ ATLÂNTIC^ DO NORDESTE. 1993. Prioridades para conservação da biodiversidade da Mata Atlântica do nordeste. Ilha de Itamaracá, Conservation International, Fundação Biodiversitas e Sociedade Nordestina de Ecologia, 1 mapa, escala 1:2.500.000.

Zimmer, J.T. 1936. Studies of Peruvian birds. No. XXIV. Notes on Pachyramphus, Platypsaris, Tityra, and Pyroderus. Amer. Mus. Novit. 894: 1-26.

Recebido em 17.VI.1999; aceito em 18.VIII. 2000. 